Project No. 09-768

\title{
Corrosion and Creep of Candidate Alloys in High Temperature Helium and Steam Environments for the \\ NGNP
}

\section{Reactor Concepts RD\&D}

Dr. Gary Was

University of Michigan

Sue Lesica, Federal POC Laura Carroll, Technical POC

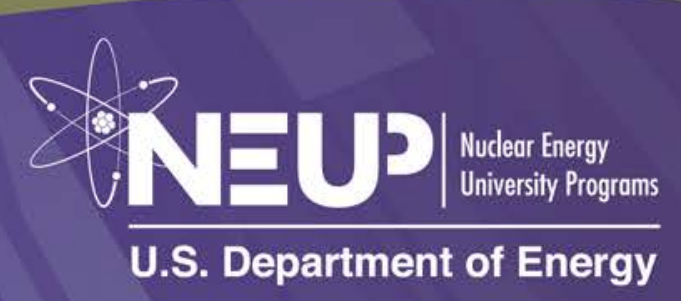




\section{FINAL REPORT}

Project Title: $\quad$ Corrosion and Creep of Candidate Alloys in High Temperature Helium and Steam Environments for the NGNP

Covering Period: $\quad$ October 1, 2009 - March 31, 2013

Date of Report: June 30, 2013

Recipient: $\quad$ University of Michigan

2355 Bonisteel Blvd

Ann Arbor, MI 48109-2104

Award Number: $\quad 87993$

Project Number: $\quad 09-768$

Principal

Investigator:

Project Objective:

Background:
Gary S. Was, 734 763-4675,gsw@umich.edu

J. W. Jones, 734 764-7503, jonesjwa@umich.edu

This project aims to understand the processes by which candidate materials degrade in $\mathrm{He}$ and supercritical water/steam environments characteristic of the current NGNP design. We will focus on understanding the roles of temperature, and carbon and oxygen potential in the $750-850^{\circ} \mathrm{C}$ range on both uniform oxidation and selective internal oxidation along grain boundaries in alloys 617 and $800 \mathrm{H}$; investigating both the uniform and localized oxidation behavior of alloy $800 \mathrm{H}$ in supercritical water in the temperature range $500-600^{\circ} \mathrm{C}$; and examining the application of static and cyclic stresses in combination with impure He environments in the temperature range $750-850^{\circ} \mathrm{C}$ over a range of oxygen and carbon potentials in helium. Combined, these studies will elucidate the potential high damage rate processes in environments and alloys relevant to the NGNP.

Both thermodynamic calculations and experimental surface stability studies confirm that degradation during high temperature exposure or during creep in impure He environments can be accelerated by decarburization processes. However, our thermodynamic calculations indicate that for the practical ranges of carbon and oxygen potentials achievable in the NGNP, decarburization will not occur at temperatures below $\sim 900^{\circ} \mathrm{C}$. Rather, oxidation and carburization will be favored. Thus in the temperature range $750-850^{\circ} \mathrm{C}$, oxidation and carburization will be the degradation modes. In addition to oxidation, mechanical loading will play an important role in the degradation of alloys in these environments. Yet a complete understanding of the combined influence of static and cyclic stresses and environment on life limiting damage accumulation does not currently exist, although limited research has shown that synergies exist between stress and environmental degradation. It is, therefore, reasonable to expect that grain boundary oxidation may substantially degrade mechanical properties such as creep. 


\section{Executive Summary}

The objective of this project is to understand the processes that degrade candidate intermediate heat exchanger (IHX) and steam generator (SG) materials selected for the current NGNP design. Surface and internal oxidation as well as static and cyclic creep deformation of the primary candidate IHX alloy, Alloy617, was studied in representative IHX helium chemistries at $750-850^{\circ} \mathrm{C}$. Alloy $800 \mathrm{H}$ is the primary candidate alloy for SG use and its oxidation behavior was investigated in supercritical water in temperature range $500-600^{\circ} \mathrm{C}$. These studies will elucidate the potential high damage rate processes in environments and alloys relevant to the NGNP.

Surface and internal oxidation kinetics of IN617 in He-CO- $\mathrm{CO}_{2}$ environments was studied at $750-850^{\circ} \mathrm{C}$ for up to $500 \mathrm{~h}$. IN617 will form $26-84 \mu \mathrm{m}$ thick surface $\mathrm{Cr}_{2} \mathrm{O}_{3}$ and $114-426 \mu \mathrm{m}$ deep intergranular $\mathrm{Al}_{2} \mathrm{O}_{3}$ during the total $\mathrm{IHX}$ service lifetime of 60 years at temperatures 750 $850^{\circ} \mathrm{C}$. The activation energies for the parabolic surface and intergranular Al oxidation were determined as $161.6 \mathrm{~kJ} / \mathrm{mole}$ and $199.3 \mathrm{~kJ} / \mathrm{mole}$, respectively. Surface and internal oxidation kinetics of IN617 strongly depended on the He-CO- $\mathrm{CO}_{2}$ composition especially during the first $150 \mathrm{~h}$ of oxidation. Internal oxidation kinetics of IN617 was also studied in $\mathrm{Cr}-\mathrm{Cr}_{2} \mathrm{O}_{3} \mathrm{Rh}$ hines packs in an effort to reduce the ambient oxygen partial pressure to the equilibrium dissociation oxygen partial pressure of $\mathrm{Cr}_{2} \mathrm{O}_{3}$. Rhines pack samples exhibited approximately $60 \%$ less intergranular and transgranular oxide depth than that measured in IN617 samples exposed to both $\mathrm{He}-\mathrm{CO} / \mathrm{CO}_{2}=9$ and $\mathrm{He}-\mathrm{CO} / \mathrm{CO}_{2}=1320$ at $850^{\circ} \mathrm{C}$ for $500 \mathrm{~h}$. The results suggested that the surface $\mathrm{Cr}_{2} \mathrm{O}_{3}$ scale maybe permeable to gas molecules and both surface and internal oxidation of IN617 may be controlled by the surface adsorption of the dilute gas molecules present in the environment.

A creep system was designed and validated to study the coupled effect of stress and environment on the static and cyclic creep deformation of Alloy 617 at $800^{\circ} \mathrm{C}$ in controlled helium environments. Static and cyclic creep tests were conducted in three different chemistries (slightly oxidizing, $\mathrm{He}-8 \mathrm{ppm} \mathrm{O}_{2}$; pure helium, He-0.1ppm $\mathrm{O}_{2}$, and slightly carburizing/oxidizing, $\mathrm{He}-\mathrm{CO} / \mathrm{CO}_{2}=1320$ ) at $800^{\circ} \mathrm{C}$. The creep tests were not conducted up to failure but were interrupted at relatively the same strains. It was observed that the creep deformation could have an influence in the surface degradation of Alloy 617 even though the mechanical deformation was not sufficient to cause bulk damage in the alloy (formation of cavities). Cyclic loading induced more damage on the alloy compared to static loading. However, no conclusive remarks can be made yet on the effect of the type of stress applied. This determination is still difficult to make since both creep and oxidation are time dependent mechanisms and the synergy of the two cannot be rule out.

Supercritical water exposures were conducted at $500-600^{\circ} \mathrm{C}$ for up to $500 \mathrm{~h}$. IN617 exhibited far more superior oxidation resistance compared to $800 \mathrm{H}$. The activation energy for oxidation of IN617 and $800 \mathrm{H}$ were determined as $103 \mathrm{~kJ} / \mathrm{mol}$ and $186 \mathrm{~kJ} / \mathrm{mol}$, respectively. 


\section{Major Accomplishments}

The following sections describe the major accomplishments or outcomes in this program. They are presented in a form that focuses on the key results and conclusions. Details of the experiments and the full set of results are available in the quarterly reports and are referenced herein rather than repeated. The overall conclusions of these accomplishments are summarized in section 3 .

Short-term oxidation kinetics of IN617 is determined as a function of impure helium composition and temperature. The life-limiting process was intergranular Al oxidation as its rate was 18-25 times greater than that of the surface oxidation.

Oxidation of IN617 is investigated in HTGR helium equivalent $\mathrm{He}-\mathrm{CO} / \mathrm{CO}_{2}=9$ (Pco $=13.5$ molppm) and $\mathrm{He}-\mathrm{CO} / \mathrm{CO}_{2}=1320(\mathrm{Pco}=1980 \mathrm{molppm})$ environments at $750-850^{\circ} \mathrm{C}$ for up to 500h.Experiments were designed to determine the steady-state surface and internal oxidation kinetics during the shortest possible exposure time. The ultimate goal was to assess the compatibility of IN617 for IHX use by extrapolating the measured oxidation rates to the desired service lifetime of this component. The detailed experimental procedure was described in a previous quarterly report [1]. Weight gain kinetics exhibited significant deviations from the parabolic law, as the time exponents (n) measured were in the range of 0.58-0.81 (Figure 1). Weight gain kinetics reflected the combined effects of surface and internal oxidation, as well as possible carburization of the alloy. These degradation modes progressed at different rates and did not contribute equally to the measured weight gain. Hence, the weight gain kinetics were not considered as the primary measure to assess the overall corrosion kinetics of IN617. Instead, the kinetics of surface $\mathrm{Cr}_{2} \mathrm{O}_{3}$ growth and internal $\mathrm{Al}_{2} \mathrm{O}_{3}$ penetration were studied separately. Figure 2 shows the characteristic dimension of each scale plotted as a function of time assuming that the parabolic oxidation kinetics prevailed. The best curve fits for these parameters indeed slightly deviated from the parabolic law. Measured surface $\mathrm{Cr}_{2} \mathrm{O}_{3}$ thickness values corresponded to at least $80 \%$ of the weight gain measured in each condition. However, intergranular $\mathrm{Al}_{2} \mathrm{O}_{3}$ oxidation was the life-limiting process for IN617 as its rate constant, $k_{P}(I)$, was 18-25 greater than that of surface oxidation, $k_{P}(S)$, depending on the test temperature. The projection of the measured rates of oxidation to the IHX service lifetime of 60 years yielded surface $\mathrm{Cr}_{2} \mathrm{O}_{3}$ formation of thickness $26-84 \mu \mathrm{m}$ and intergranular penetration of $\mathrm{Al}_{2} \mathrm{O}_{3}$ to $114-426 \mu \mathrm{m}$ at temperatures $750-850^{\circ} \mathrm{C}$. In this temperature range, the activation energies for the parabolic surface and intergranular Al oxidation are determined as $161.6 \mathrm{~kJ} / \mathrm{mole}$ and $199.3 \mathrm{~kJ} / \mathrm{mole}$, respectively. The activation energy for surface oxidation was in excellent agreement with the activation energy for oxidation of pure $\mathrm{Cr}$ at $700-1100^{\circ} \mathrm{C}(157 \mathrm{~kJ} / \mathrm{mole})$ [2]. Extrapolation of the $k_{P}(S)$ data to $950^{\circ} \mathrm{C}$ also agreed well with the surface oxidation rate constant data reported by Cabet and Duprey [3] for Alloy 617 exposed to a multi-component VHTR equivalent environment at $950^{\circ} \mathrm{C}$, at much higher flow rates $(800-1600 \mathrm{ml} / \mathrm{min}$ ) (Figure 3). Extrapolation 
of the $k_{P}(I)$ values remained greater than the value reported by Cabet and Duprey [3], most probably because the authors reported a combined rate for intergranular and transgranular oxidation.

Even though the majority of the IN617 weight gain in $\mathrm{He}-\mathrm{CO}-\mathrm{CO}_{2}$ environments was due to surface $\mathrm{Cr}_{2} \mathrm{O}_{3}$ formation; intergranular $\mathrm{Al}_{2} \mathrm{O}_{3}$ penetration was the life-limiting process. The results suggest that in the $750-850^{\circ} \mathrm{C}$ range, the minimum $I H X$ piping wall thickness will be dictated by intergranular $\mathrm{Al}_{2} \mathrm{O}_{3}$ penetration.

\section{Short-term IN617 surface and internal oxidation kinetics showed significant dependence on the helium composition.}

IN617 samples exposed to $\mathrm{He}-\mathrm{CO} / \mathrm{CO}_{2}=1320$ exhibited greater weight gains than the samples exposed to $\mathrm{He}-\mathrm{CO} / \mathrm{CO}_{2}=9$ at temperatures $750-850^{\circ} \mathrm{C}$. The difference between the measured weight gains was very significant within the first $150 \mathrm{~h}$ of exposure in both environments at all temperatures. This time period may indicate that the oxidation was still in a transient regime, such that the oxidation rate was highly dependent on the gas flow rate and the concentration of the reactant species in the dilute gas stream. Surface and intergranular oxidation rate constants measured in $\mathrm{He}-\mathrm{CO} / \mathrm{CO}_{2}=1320$ were almost 2 times greater than that in $\mathrm{He}-\mathrm{CO} / \mathrm{CO}_{2}=9$ at $850^{\circ} \mathrm{C}$ (Figure 3 ). The difference in the $k_{P}(I)$ values measured in both environments was especially striking. $k_{P}(I)$ is directly proportional to the oxygen permeability (solubility $\mathrm{x}$ diffusivity) in the alloy. The oxygen diffusivity in each environment must be the same as the samples were exposed to both environments at the same temperature. Therefore, oxygen solubility in the sample exposed to $\mathrm{He}-\mathrm{CO} / \mathrm{CO}_{2}=1320$ was greater than that in the sample exposed to $\mathrm{He}-\mathrm{CO} / \mathrm{CO}_{2}=9$. This is not expected if a perfectly dense and well-adhered surface $\mathrm{Cr}_{2} \mathrm{O}_{3}$ scale would form. Therefore, the surface $\mathrm{Cr}_{2} \mathrm{O}_{3}$ scale may be permeable to gas molecules and oxygen solubility in the alloy may be proportional to the partial pressures of the molecules permeated to the alloy/oxide interface. Both surface and internal oxidation of IN617 may be controlled by the surface adsorption of the dilute gas molecules present in the environment. However, it is not immediately clear whether increasing the gas flow rate may diminish the observed difference between the $k_{P}(S)$ and $k_{P}(I)$ in both environments at a given exposure temperature.

The dependence of $k_{P}(I)$ on the composition of the $\mathrm{He}-\mathrm{CO}-\mathrm{CO}_{2}$ environments suggests that the oxygen solubility in the alloy may greatly be influenced by the permeation of the gas molecules through the surface $\mathrm{Cr}_{2} \mathrm{O}_{3}$ scale. 
Samples tested at the dissociation oxygen partial pressure of $\mathrm{Cr}_{2} \mathrm{O}_{3}$ exhibited $60 \%$ less internal Al oxidation compared to samples exposed to the $\mathrm{He}-\mathrm{CO}-\mathrm{CO}_{2}$ environments at $850^{\circ} \mathrm{C}$. The $\mathrm{Cr}_{2} \mathrm{O}_{3}$ formed in $\mathrm{He}$-CO-CO${ }_{2}$ environments does not make an effective diffusion barrier.

Internal oxidation in an alloy is driven by oxygen permeability, which is a function of the oxygen solubility and diffusivity. Oxygen solubility is proportional to the oxygen partial pressure attained at the alloy surface according to Sievert's Law and can only be measured accurately if the ambient oxygen partial pressure is known. Rhines packs [4] are very effective in sustaining very low oxygen partial pressures in an evacuated capsule filled with a mixture of powdered metal and its oxide. Samples of IN617 were tested in $\mathrm{Cr}^{-} \mathrm{Cr}_{2} \mathrm{O}_{3}$ Rhines packs in an effort to suppress the surface $\mathrm{Cr}_{2} \mathrm{O}_{3}$ formation and to study the kinetics of internal oxidation at a known ambient oxygen partial pressure set by the $\mathrm{Cr}-\mathrm{Cr}_{2} \mathrm{O}_{3}$ equilibrium at $850^{\circ} \mathrm{C}$ for up to $1000 \mathrm{~h}$. The goal is to compare the rate of internal $\mathrm{Al}$ oxidation measured in $\mathrm{Cr}_{-}-\mathrm{Cr}_{2} \mathrm{O}_{3}$ Rhines packs with that measured in samples exposed to the He-CO- $\mathrm{CO}_{2}$ environments, and to determine if the surface $\mathrm{Cr}_{2} \mathrm{O}_{3}$ forming in the latter environment provides a tenacious barrier against inward oxygen flux. The detailed experimental procedure about $\mathrm{Cr}-\mathrm{Cr}_{2} \mathrm{O}_{3}$ Rhines pack sample preparation and exposure was described in a previous quarterly report [1]. Rhines pack IN617 samples exposed to $850^{\circ} \mathrm{C}$ for $500 \mathrm{~h}$ exhibited much less weight gain and approximately $60 \%$ less intergranular and transgranular oxide depth than that measured in IN617 samples exposed to both $\mathrm{He}-\mathrm{CO} / \mathrm{CO}_{2}$ $=9$ and $\mathrm{He}-\mathrm{CO} / \mathrm{CO}_{2}=1320$ at $850^{\circ} \mathrm{C}$ for the same time (Figures 1 and 2). Oxygen permeability in IN617 is much greater in $\mathrm{He}-\mathrm{CO}-\mathrm{CO}_{2}$ environments than that at the dissociation oxygen partial pressure of $\mathrm{Cr}_{2} \mathrm{O}_{3}$ at $850^{\circ} \mathrm{C}$. This could be attributed to the greater oxygen solubility in samples exposed to $\mathrm{He}-\mathrm{CO}-\mathrm{CO}_{2}$ environments than that in Rhines pack samples as the oxygen diffusivity in both cases was identical. It appears that the formation of $\mathrm{Cr}_{2} \mathrm{O}_{3}$ on the surface did not sustain the dissociation oxygen partial pressure of $\mathrm{Cr}_{2} \mathrm{O}_{3}$ at the alloy/oxide interface. The oxygen transport to the alloy/oxide interface was not limited by solid state diffusion of oxygen anions through the oxide scale as short-circuit diffusion paths were probably present in the oxide. Studies investigating the multicomponent gas-alloy interactions at high temperatures revealed that surface scales such as $\mathrm{Cr}_{2} \mathrm{O}_{3}$ are indeed permeable to molecular oxidants such as $\mathrm{CO}, \mathrm{N}_{2}$, $\mathrm{SO}_{2}$ and $\mathrm{H}_{2} \mathrm{O}[5-9]$.

The greater rate of internal Al oxidation in $\mathrm{He}-\mathrm{CO}-\mathrm{CO}_{2}$ environments than that in Rhines pack exposures could be attributed to the permeation of $\mathrm{CO}$ and $\mathrm{CO}_{2}$ molecules through the surface $\mathrm{Cr}_{2} \mathrm{O}_{3}$ scale.

Heat-to-heat variation in the kinetics of surface and internal oxidation of Alloy 617 upon exposure to $\mathrm{He}-\mathrm{CO} / \mathrm{CO}_{2}=1320$ at $850^{\circ} \mathrm{C}$ was negligible.

Two different heats of Alloy617 (IN617 and Nicofer 5520Co) were tested in $\mathrm{He}-\mathrm{CO} / \mathrm{CO}_{2}=1320$ at $850^{\circ} \mathrm{C}$ for $225 \mathrm{~h}$. The goal was to investigate the effects of possible differences in the 
microstructure, composition and grain size of the alloys on the oxidation kinetics in $\mathrm{He}-\mathrm{CO}-\mathrm{CO}_{2}$ environments. IN617 (heat \# XXX2323 U K) was obtained from Specialty Metals Inc. in the form of a plate with an average grain size of $65 \mu \mathrm{m}$. Nicofer 5520Co (heat \# 314626) is the alloy that has been used for the creep tests throughout this project and was provided by Thyssen Krupp VDM USA, Inc in the form of a plate with an average grain size of $129 \mu \mathrm{m}$. The compositions of both alloys were very similar and conformed to ASTM standards. Both alloys were solution annealed at $1175^{\circ} \mathrm{C}$; however globular intergranular and intragranular $\mathrm{Cr}$ rich $\mathrm{M}_{23} \mathrm{C}_{6}$ and Mo rich $\mathrm{M}_{6} \mathrm{C}$ carbides aligned along the rolling direction in the as-received IN617 microstructure [10]. As-received Nicofer 5520Co microstructure contained extremely small amounts of Mo rich $\mathrm{M}_{6} \mathrm{C}$ carbides and $\mathrm{Ti}(\mathrm{C}, \mathrm{N})$ precipitates [11].

IN617 and Nicofer 5520Co exhibited almost identical weight gains upon exposure to He$\mathrm{CO} / \mathrm{CO}_{2}=1320$ at $850^{\circ} \mathrm{C}$ for $225 \mathrm{~h}$ (Figure 1). The difference between the average surface $\mathrm{Cr}_{2} \mathrm{O}_{3}$ thickness, intergranular and transgranular $\mathrm{Al}_{2} \mathrm{O}_{3}$ depth values measured for both heats also remained statistically insignificant (Figures $2 \mathrm{a}$ and $\mathrm{b}$ ). These results showed that heat-to-heat variation did not significantly influence the Alloy 617 surface and internal oxidation kinetics in $\mathrm{He}-\mathrm{CO} / \mathrm{CO}_{2}$ environments.

Despite the differences in as-received microstructure and grain size, both heats of Alloy617 exhibited very similar oxidation rates in $\mathrm{He}-\mathrm{CO} / \mathrm{CO}_{2}=1320$ at $850^{\circ} \mathrm{C}$.

\section{IN617 exhibited superior oxidation resistance compared to $800 \mathrm{H}$ in deaerated supercritical water $(\mathrm{SCW})$ at $500-600^{\circ} \mathrm{C}$. The activation energies for oxidation of IN617 and $800 \mathrm{H}$ were determined as $103 \mathrm{~kJ} / \mathrm{mol}$ and $186 \mathrm{~kJ} / \mathrm{mol}$, respectively.}

Samples of IN617 and $800 \mathrm{H}$ were exposed to deaerated SCW at temperatures $500-600^{\circ} \mathrm{C}$ for up to $500 \mathrm{~h}$. The experimental procedure was described in detail in a prior quarterly progress report [12]. $800 \mathrm{H}$ samples exhibited 13 - 70 times greater weight gain than IN617 samples did at 500 $600^{\circ} \mathrm{C}$ (Figure 4). The activation energy for the oxidation of Alloy $800 \mathrm{H}$ was calculated as 186 $\mathrm{kJ} / \mathrm{mol}$ by plotting the natural logarithm of the oxidation rate constant as a function of the inverse temperature (Figure 5). The data was in good agreement with the activation energy for the oxidation of Alloy 800 in deaerated SCW at $450-600^{\circ} \mathrm{C}$ reported as $178 \mathrm{~kJ} / \mathrm{mol}$ [13]. The activation energy for the oxidation of alloy IN617 was $103 \mathrm{~kJ} / \mathrm{mol}$. The measured activation energy may not fully represent the actual oxidation kinetics of IN617 in deaerated SCW as the weight gain measured at $600^{\circ} \mathrm{C}$ was unexpectedly low. The weight gain rate constant measured for Alloy $800 \mathrm{H}$ was approximately 5 orders of magnitude greater than that for IN617.

Alloy $800 H$ exhibited 5 orders of magnitude greater oxidation rates than did IN617 in deaerated $S C W$ environment at temperatures $500-600^{\circ} \mathrm{C}$. 


\section{The establishment of a dedicated creep system enabled the combination of cyclic loading with creep experiments of Alloy 617 in controlled helium environments.}

Building on the knowledge and success of an exposure system described elsewhere [14], the Controlled-Impurity Helium Flow Creep system was constructed to conduct both static and cyclic creep experiments in helium with controlled levels of impurities such as $\mathrm{CO}$ and $\mathrm{CO}_{2}$. Figures 6 and 7 show the schematic and the photograph of the system consisting of three major sections: a gas mixing section, an exposure-mechanical testing section, and a gas analysis section. The gas mixing section provides the capability of obtaining the desired concentration of $\mathrm{CO}$ and $\mathrm{CO}_{2}$ inside the creep retort using premixed bottle gases of helium with a given level of one type of impurity and a series of mass flow controllers. The helium with controlled levels of $\mathrm{CO}$ and $\mathrm{CO}_{2}$ is passed through the exposure-mechanical testing section in which the sides of the pin-loaded specimen are exposed to the flowing helium containing varying levels of $\mathrm{CO}$ and $\mathrm{CO}_{2}$. A needle valve at the entrance of the furnace is used to control the flow rate of the gas mixture through this section. The $\mathrm{CO}$ and $\mathrm{CO}_{2}$ levels in the helium are analyzed continuously both before and after the entry into the furnace using the discharge ionization detector gas chromatograph in the analysis section. Experimental variables such as flow rates of gases and concentration levels of impurities are continuously monitored using a personal computer. The sections hereafter described the different experiments in details.

The gas mixing section consists of 3 pre-mixed gas bottles and 3 mass flow controllers. To obtain the gas mixture with the target concentration of each impurity, a pre-mixed gas cylinder of helium with a certified level of one impurity, and a controlled amount of another impurity from a different certified pre-mixed bottle were combined using electronic mass flow controllers. The resulting gas mixture was then diluted, if required, by mixing it with research grade helium of $99.9999 \%$ purity. The electronic mass flow controller used for gas mixing had an accuracy of \pm 1 $\mathrm{ml} / \mathrm{min}$ with a full scale operation range of 0 to $200 \mathrm{ml} / \mathrm{min}$, and was capable of withstanding pressure up to 500 PSIG. All the components involved in transporting and mixing the gases were made from 316 stainless steel. Whenever possible, weld fittings were used for connecting lines from different gas bottles to avoid the in-leakage of air.

The exposure-mechanical section, as the name suggests, is where the pin-loaded specimen is exposed to high temperatures (via the furnace), flowing helium containing varying levels of the named impurities, and a static or cyclic load applied via the load train. The main components of the system are the creep frame, the specimen chamber, the servomotor and the servo-controller unit (Figs. 6-8). The creep frame was made of stainless steel columns and a base for assembling the load train, the furnace and the servomotor unit. The specimen chamber had a minimum volume (38 $\mathrm{mm}$ internal diameter, $42 \mathrm{~mm}$ external diameter) necessary to house the specimen, the thermocouple wires, the load train, and the porous alumina within the hot zone. A porous alumina barrier was used as a heat shield for the O-rings in the chamber end seals (made of 
stainless steel 304). In addition, chilled water was circulated around the end seals. Three thermocouples were inserted into the quartz tube from the bottom end seal and were placed within the quartz tube such that temperatures were obtained at the middle and both ends of the gauge section of the specimen. The load train components that are directly inside the high temperature zone of the furnace were carefully designed to withstand both high loads (strength and creep resistance) as well as resist corrosion. The load train components near the furnace were made of high-temperature molybdenum alloy (TZM) that exhibited high strength at $1000^{\circ} \mathrm{C}$. The specimen grips were designed using creep-resistant Mar-M-247 alloys. In order to protect these components from corrosion in impure helium, the TZM cylindrical load train components were coated with high temperature boron nitride lubricant and encased in $99.99 \%$ pure alumina tubes with almost negligible clearance. Since the thermal expansion coefficient of TZM is very low, the components did not exhibit any significant thermal expansion that would crack the alumina casings.

Strain measurement was done near the load-line (bottom) as shown in Figure 8 . It was demonstrated that the measurement of strain can be determined from two different locations with similar results (Figure 9). Usually, the strains are measured directly from the gauge section in the hot zone. However, if the strains are determined via the load line displacement instead of the gauge length deformation, the creep system is simplified since extra components near the specimen and, which are exposed to gaseous environment, are reduced. This precludes any error in estimating the gas consumptions during the corrosion-creep testing.

Mechanical experiments were conducted by applying static and cyclic stresses in combination with impure helium environments. A digitally controlled servo motor creep controller with feedback mechanism enabled the application of both static and cyclic stresses. This servo motor, as shown in Figure 8, served to replace dead weights used conventionally and was capable of maintaining constant load conditions and sustained cyclic motion. The motor is controlled via the control panel from where one can manually or remotely configure the control of the load and displacement in real-time. A built-in waveform generator can be programmed to cycle or ramp the control point for the duration of the creep tests. Since the servo motor contains a closed loop digital PID controller, the control point was accurately manipulated in real time. The control panel has an RS-232 serial port enabling a computer to have full control of the servo motor for even more functionality. The PC attached to it enabled, in conjunction with a language such as LabVIEW, the control of the unit's operation or even the collection of data during the test.

The last section was the gas-analysis section, which consisted of the DIDGC and the PC (Figs. 6 and 7). The DIDGC was used to continuously analyze the gas mixture both before and after the exposure section, and the PC was used to control the GC. The details of the functioning of the gas chromatograph have been described elsewhere [14]. 
A dedicated creep system that enables the combination of cyclic loading with creep experiments in impure helium gasses has been design, built and validated through a careful choice of materials for the environmental chamber, precise mixing of gases and gas analysis, and accurate control of load.

The coupling of stress and environment during static and cyclic creep of Alloy 617 at $800^{\circ} \mathrm{C}$ in controlled helium environments revealed that mechanical loading increased the extent of surface degradation.

Static and cyclic creep tests were conducted in three different environments (slightly oxidizing, $\mathrm{He}-8 \mathrm{ppm} \mathrm{O}_{2}$; pure helium, He-0.1ppm $\mathrm{O}_{2}$, and slightly carburizing/oxidizing, $\mathrm{He}-\mathrm{CO} / \mathrm{CO}_{2}$ $=1320)$ at $800^{\circ} \mathrm{C}$. Creep tests were interrupted at relatively the same strains. The objective of these tests was to study the role environment on the type of degradation of Alloy 617 under both static and cyclic loading. The experimental procedures have been provided in detail elsewhere $[1,15]$. The effect of stress/strain subjected on Alloy 617 during exposure to the carburizing/oxidizing environment was studied by comparing the results of the creep test with the results of an exposure test of a similar alloy exposed at $850^{\circ} \mathrm{C}$.

The creep curves of the three tests are shown in Figure 10 and the details thereof are provided in Table 1. The creep curves follow similar trends and that the steady state creep rates are similar. The type of load applied to the specimen does not seem to have an observable effect on the creep curves as the steady state creep rates are similar. The mechanical behavior is also not influenced by the type of test environment. There seems not to be a conclusive determination of the effect of the environment on the nature of the creep curves of Alloy 617. Mino et al [16] concluded that there is no significant influence of the atmosphere on the steady-state regime of the creep of Inconel 617 under a stress of $90 \mathrm{MPa}$. This conclusion contradicts that one of Shankar [17], according to whom, the secondary creep rates of the curves for carburizing and oxidizing environments were significantly different. In fact, Shankar observed that the carburizing environment had the effect of lengthening the creep life while he identified shorter lives with the oxidizing environment. It should be noted, however, that the test environments used by Mino and Shankar are slightly different from the carburizing environment used for the tests described in this report. While all these tests are in carburizing environments, the tests in this report have a slight oxidation tendency compared to the reducing propensity of the environment in the tests by Mino and Shankar. The other reason for the different results observed in this report could reside in the nature of the tests. Mino and Shankar conducted longer creep tests up to failure. However, the tests described in this report were interrupted long before failure so that preliminary studies of the influence of creep deformation on the surface degradation could be initiated. In this study, while creep deformation is present (due to the strain of the alloy at high temperature), care was taken to interrupt the tests before any bulk degradation (formation of cavities) could take place. It might be necessary in future to consider conducting longer creep tests beyond the steady-state regime. 
Observation of the specimen surface before sectioning revealed the presence of intergranular cracks (Figs. 11-13) and no transgranular cracking was observed. Microstructural cross-sections of the crept alloy in the different environments are shown in Figs. 14-16 and the details of the internal damage are indicated in Table 2. The purity of the creep test environment seems to have an effect on the surface degradation of Alloy 617. Information shown on Table 2 clearly shows the trend of a steady increase in the number of cracks, the crack depth and the thickness of the surface oxide as the purity of the helium gas decreases (from He-0.1ppm $\mathrm{O}_{2}$ to $\mathrm{He}$ $\left.\mathrm{CO} / \mathrm{CO}_{2}=1320\right)$. It is worth distinguishing the damage on Alloy 617 in a carburizing environment. Figure 16 shows the development of cracks that are different from the ones observed in the previous two environments. The cracks in the pure and slightly oxidizing helium environments, Figs. 14 and 15 respectively, were shorter and there was no substantive presence of chromia within the cracks aside from the surface scale. The damage in the carburized alloy was more severe in two aspects. First, the lengths of the cracks were greater (Figure 16) and, second, the subsurface part of the alloy saw an increase in the presence of internal carbides (Figure 17). The cause of the presence of chromia in the cracks was not well understood and there are two possibilities. According to Schnaas and Grabke [18], the microstructure evolution of Ni-Cr-Fe alloys in a carburizing and oxidizing environment depended on the strain rate. In the case of low strain rate $\left(4 \times 10^{-9} / \mathrm{s}\right)$, carburization occurred along the grain boundaries, followed by oxidation and then the opening of cracks. They argued that, in the case of high strain rates $\left(1.3 \times 10^{-7} / \mathrm{s}\right)$, carburization was not localized at the grain boundaries but carbide formation occurred everywhere in the bulk. In the experiments described in this project, creep tests were terminated well before failure, making it difficult to compare directly with Grabke's work. However, it is worth noting that given that the strain rates $\left(10^{-8} / \mathrm{s}\right)$ are in between the low and high values given in the literature, carburization of the bulk was observed only up to a depth of $60 \mu \mathrm{m}$. The grain boundaries, on the other hand, seemed to have been oxidized following an initial carburization. Given the rapid damage on the grain boundaries as observed in these tests at these low strains, it is possible that in a longer test, the intergranular cracks would penetrate deeper into the specimen. In this way, further bulk carburization could be enhanced by way of grain boundary diffusion into the bulk than by bulk carburization occurring from the surface of the specimen. Also with a longer test, the effect of the different environments in terms of the nature of the creep curves could start to become clearer than it is in the case of the interrupted tests.

The role of stress can be seen in the comparison made between the thermally exposed and crept alloys. The experimental details of the exposed alloy were described earlier [1]. Figure 18 shows the difference in the nature of surface degradation in the two cases. In the exposed-only alloy (test conducted at $850^{\circ} \mathrm{C}$ ), the usual presence of the surface chromia and intergranular and/or transgranular oxidation can be noted. The addition of stress, however, as seen in the crept alloy (test at $800^{\circ} \mathrm{C}$ ), enhances the development of intergranular cracks possibly due to enhanced grain boundary diffusion. This comparison, even though made for tests at different temperatures, 
still shows that the effect of creep load on Alloy 617 was more damaging even at a relatively lower temperature. Mino [19] has described the role of stress on the intergranular oxidation of Alloy 617 . He observed that the applied stress significantly enhanced the intergranular oxidation and also that the penetration depth increased with creep strain and oxidation time. It is surmised that the enhanced intergranular oxidation (and consequently intergranular cracking) was attributed to the localized fracture of external oxide layers and internal oxides of aluminum due to grain boundary sliding.

While the role of stress was seen when comparing loaded versus unloaded specimens, the type of loading (cyclic or static) seemed to also play a role in the extent of surface degradation of Alloy 617. A general conclusion from Table 2 on the effect of the type of loading is that cyclic loading caused more severe damage (higher number of cracks, increased cracks depths and increased scale thickness) than static loading possibly as a result of fracture of oxide during the cyclic opening and closing of cracks. However, it should also be noted that the cyclic loading was such that during each cycle, the alloy was subjected to the maximum stress half of the time compared to the case of static stress. So, it took twice as long to reach the target strains as it did for static tests. Since creep and oxidation are both time dependent mechanisms, it is not clear if the longer time of exposure or the nature of the loading could have been responsible for the relatively severe damage. Future tests could be proposed where the loading and unloading transients of the loading cycle are reduced so that the total test time tends towards the total time at maximum stress. In this way, a more meaningful comparison between static and cyclic creep tests could be made.

The coupling of stress and environment during the creep of Alloy 617 has shown that mechanical loading increases the extent of surface degradation. The effect of stress, however, will depend on the parameters of the test: strain rate, loading type (static or cyclic), helium composition, and duration of the test.

\section{Conclusions}

- Even though the majority of the IN617 weight gain in $\mathrm{He}-\mathrm{CO}-\mathrm{CO}_{2}$ environments was due to surface $\mathrm{Cr}_{2} \mathrm{O}_{3}$ formation; the life-limiting process was intergranular $\mathrm{Al}$ oxidation as its rate was 18-25 times greater than that of the surface oxidation in temperature range of 750 $850^{\circ} \mathrm{C}$.

- Surface and internal oxidation kinetics showed significant dependence on the helium composition. The oxygen solubility in the alloy may be influenced by the partial pressures of molecular oxidants in IHX helium despite formation of a continuous surface $\mathrm{Cr}_{2} \mathrm{O}_{3}$ scale.

- The rate of internal $\mathrm{Al}$ oxidation in IN617 was much greater in $\mathrm{He}-\mathrm{CO}-\mathrm{CO}_{2}$ environments than that at the dissociation oxygen partial pressure of $\mathrm{Cr}_{2} \mathrm{O}_{3}$. This indicated that the oxygen transport across the alloy/oxide interface did not occur by solid-state means as short-circuit 
diffusion paths were probably present in $\mathrm{Cr}_{2} \mathrm{O}_{3}$. These short-circuit paths may even enable permeation of gas molecules through the surface scale.

- Heat-to-heat variation in surface and internal oxidation of Alloy 617 was negligible upon exposure to $\mathrm{He}-\mathrm{CO} / \mathrm{CO}_{2}=1320$ at $850^{\circ} \mathrm{C}$.

- Alloy $800 \mathrm{H}$ exhibited 5 orders of magnitude greater oxidation rates than IN617 did in deaerated SCW environment at temperatures $500-600^{\circ} \mathrm{C}$.

- The establishment of a dedicated creep system that enables the combination of cyclic loading with creep experiments required a careful choice of materials for the environmental chamber, correct gas mixing, careful analysis of the gas mixture into and out of the creep system, and accurate load control.

- The coupling of stress and environment during the creep of Alloy 617 at $800^{\circ} \mathrm{C}$ has shown that mechanical loading increases the extent of surface degradation. The effect of stress, however, will depend on the parameters of the test: strain rate, loading type (static or cyclic), helium composition, and duration of test.

\section{References}

[1] G.S. Was, J.W. Jones, G. Gulsoy, A.O. Okello, NEUP 09-678 Quarterly Progress Report Y4Q2, 2013.

[2] W. Smeltzer, D. Young, Oxidation properties of transition metals, Progress in Solid State Chemistry. 10 (1975) 17-54.

[3] C. Cabet, B. Duprey, Long term oxidation resistance of alloys for gas-cooled reactors, Nuclear Engineering and Design. 251 (2012) 139-145.

[4] F. Rhines, A metallographic study of internal oxidation in the alpha solid solutions of copper, AIME TRANS. 137 (1940).

[5] D.J. Young, S. Watson, High-temperature corrosion in mixed gas environments, Oxidation of Metals. 44 (1995) 239-264.

[6] D.J. Young, Simultaneous oxidation and carburisation of chromia forming alloys, International Journal of Hydrogen Energy. 32 (2007) 3763-3769.

[7] X.G. Zheng, D.J. Young, High-temperature corrosion of Cr2O3-forming alloys in COCO2-N2 atmospheres, Oxidation of Metals. 42 (1994) 163-190.

[8] X.G. Zheng, D.J. Young, Sulphide formation after pre-oxidation of chromia formers, Corrosion Science. 38 (1996) 1877-1897. 
[9] F. Rouillard, C. Cabet, K. Wolski, M. Pijolat, Oxidation of a chromia-forming nickel base alloy at high temperature in mixed diluted $\mathrm{CO} / \mathrm{H} 2 \mathrm{O}$ atmospheres, Corrosion Science. 51 (2009) 752-760.

[10] D. Kumar, R.R. Adharapurapu, T.M. Pollock, G.S. Was, High-Temperature Oxidation of Alloy 617 in Helium Containing Part-Per-Million Levels of CO and CO2 as Impurities, Metallurgical and Materials Transactions A. 42 (2011) 1245-1265.

[11] G.S. Was, J.W. Jones, G. Gulsoy, A.O. Okello, NEUP 09-678 Quarterly Progress Report Y2Q3, 2011.

[12] G.S. Was, J.W. Jones, G. Gulsoy, A.O. Okello, NEUP 09-678 Quarterly Progress Report Y2Q4, 2011.

[13] M. Fulger, D. Ohai, M. Mihalache, M. Pantiru, V. Malinovschi, Oxidation behavior of Incoloy 800 under simulated supercritical water conditions, Journal of Nuclear Materials. 385 (2009) 288-293.

[14] D. Kumar, C.J. Torbet, G.S. Was, A facility for conducting high-temperature oxidation experiments of alloys in helium environments containing part per million levels of impurities, Measurement Science and Technology. 20 (2009) 095708.

[15] G.S. Was, J.W. Jones, G. Gulsoy, A.O. Okello, NEUP 09-678 Quarterly Progress Report Y3Q4, (2012).

[16] K. Mino, Effect of Simulated HTR Helium Atmosphere on Creep Rupture Properties of Nickel-Base Wrought Alloys, Tokyo 135-91. Trans. Iron Steel Inst. Japan. 23 (1983) 815823.

[17] P. Shankar, K. Natesan, Effect of trace impurities in helium on the creep behavior of Alloy 617 for very high temperature reactor applications, Journal of Nuclear Materials. 366 (2007) 28-36.

[18] a. Schnaas, H.J. Grabke, High-temperature corrosion and creep of Ni-Cr-Fe alloys in carburizing and oxidizing environments, Oxidation of Metals. 12 (1978) 387-404.

[19] K. Mino, A. Oktomo, Y. Saiga, The effect of stressing on the intergranular oxidation of Inconel 617, Journal of the Japan Institute of Metals. 44 (1980) 1397-1403. 
Table 1. Interrupted creep results on Alloy 617 at $800^{\circ} \mathrm{C}$ in different environments.

\begin{tabular}{|l|l|c|c|c|}
\hline \multicolumn{1}{|c|}{ Environment } & \multicolumn{1}{c|}{ Load } & Strain (\%) & $\begin{array}{c}\text { Minimum Creep } \\
\text { Rate (10 }\end{array}$ & Test Time (h) \\
\hline \multirow{2}{*}{$\mathrm{He}-8 \mathrm{ppm} \mathrm{O} \mathrm{O}_{2}$} & Static (50 MPa) & 2.2 & 1.1 & 258 \\
\cline { 2 - 5 } & Cyclic (10-50 MPa) & 2.4 & 1.3 & 685 \\
\hline $\mathrm{He}-<0.1 \mathrm{ppm} \mathrm{O}_{2}$ & Static (50 MPa) & 1.9 & 1.7 & 211 \\
\cline { 2 - 5 } & Cyclic (10-50 MPa) & 2.3 & 0.94 & 690 \\
\hline $\mathrm{He}-\mathrm{CO} / \mathrm{CO}_{2}=1320$ & Static (50 MPa) & 1.7 & 1.3 & 206 \\
\hline $\mathrm{He}-\mathrm{CO} / \mathrm{CO}_{2}=1000$ & Cyclic (10-50 MPa) & 2.1 & 1.4 & 553 \\
\hline
\end{tabular}

Table 2. Characterization of surface cracks in Alloy 617 crept at $800^{\circ} \mathrm{C}$ in different environments.

\begin{tabular}{|c|c|c|c|c|c|}
\hline Environment & Load & $\begin{array}{c}\text { Strain } \\
(\%)\end{array}$ & $\begin{array}{c}\text { Number of } \\
\text { cracks }\end{array}$ & $\begin{array}{c}\text { Average } \\
\text { crack depth } \\
(\mu \mathrm{m})\end{array}$ & $\begin{array}{c}\text { Average } \\
\text { oxide } \\
\text { thickness } \\
(\mu \mathrm{m})\end{array}$ \\
\hline \multirow{2}{*}{$\mathrm{He}-8 p p m \mathrm{O}_{2}$} & Static (50 MPa) & 2.2 & 22 & $13.4 \pm 5.3$ & $1.1 \pm 0.4$ \\
\hline & Cyclic (10-50 MPa) & 2.4 & 41 & $13.6 \pm 6.2$ & $1.5 \pm 0.4$ \\
\hline \multirow{2}{*}{$\mathrm{He}-<0.1 p p m \mathrm{O}_{2}$} & Static (50 MPa) & 1.9 & 6 & $7.5 \pm 2.4$ & $1.0 \pm 0.3$ \\
\hline & Cyclic (10-50 MPa) & 2.3 & 34 & $13.8 \pm 6.4$ & $1.3 \pm 0.3$ \\
\hline $\mathrm{He}-\mathrm{CO} / \mathrm{CO}_{2}=1320$ & Static (50 MPa) & 1.7 & 31 & $34.3 \pm 21.9$ & $2.0 \pm 0.4$ \\
\hline $\mathrm{He}-\mathrm{CO} / \mathrm{CO}_{2}=1000$ & Cyclic (10-50 MPa) & 2.1 & 45 & $48.9 \pm 14.1$ & $3.5 \pm 0.4$ \\
\hline
\end{tabular}




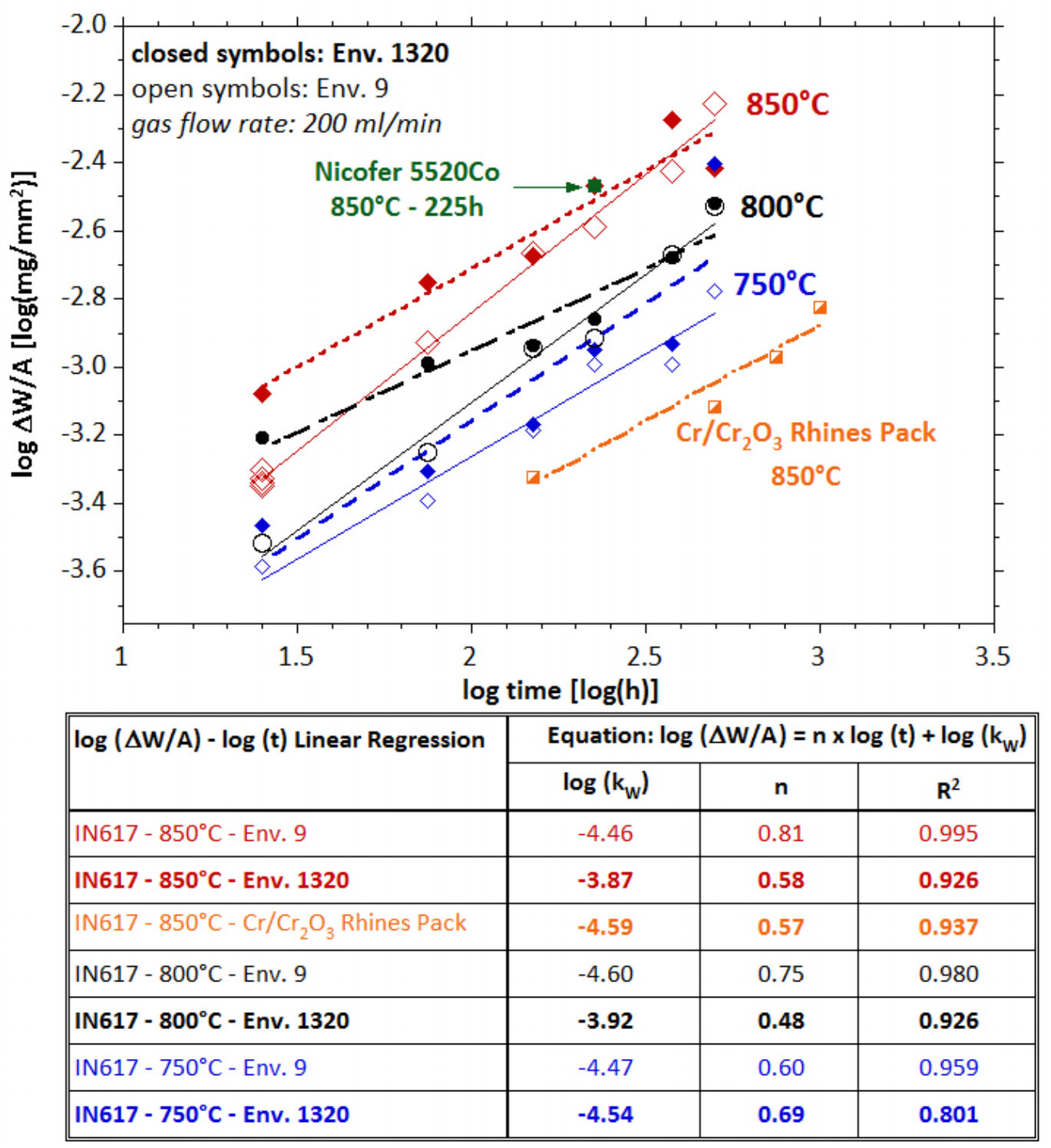

Figure 1. $\log \Delta W / A-\log t$ plot of the specific weight gain kinetics measured for IN617 samples exposed to $\mathrm{He}-\mathrm{CO} / \mathrm{CO}_{2}=9(\mathrm{Pco}=13.5 \mathrm{molppm})$ and $\mathrm{He}-\mathrm{CO} / \mathrm{CO}_{2}=1320(\mathrm{Pco}=1980 \mathrm{molppm})$ at $750-850^{\circ} \mathrm{C}$; Nicrofer 5520Co sample exposed to $\mathrm{He}-\mathrm{CO} / \mathrm{CO}_{2}=1320(\mathrm{Pco}=1980 \mathrm{molppm})$ at $850^{\circ} \mathrm{C}$ for $225 \mathrm{~h}$ and $\mathrm{IN} 617 \mathrm{Cr}-\mathrm{Cr}_{2} \mathrm{O}_{3}$ Rhines Pack samples tested at $850^{\circ} \mathrm{C}$. ( $R^{2}$ is a statistical measure of how well the regression line approximates the real data points and a value of 1.0 indicates that the regression line perfectly fits the data). 


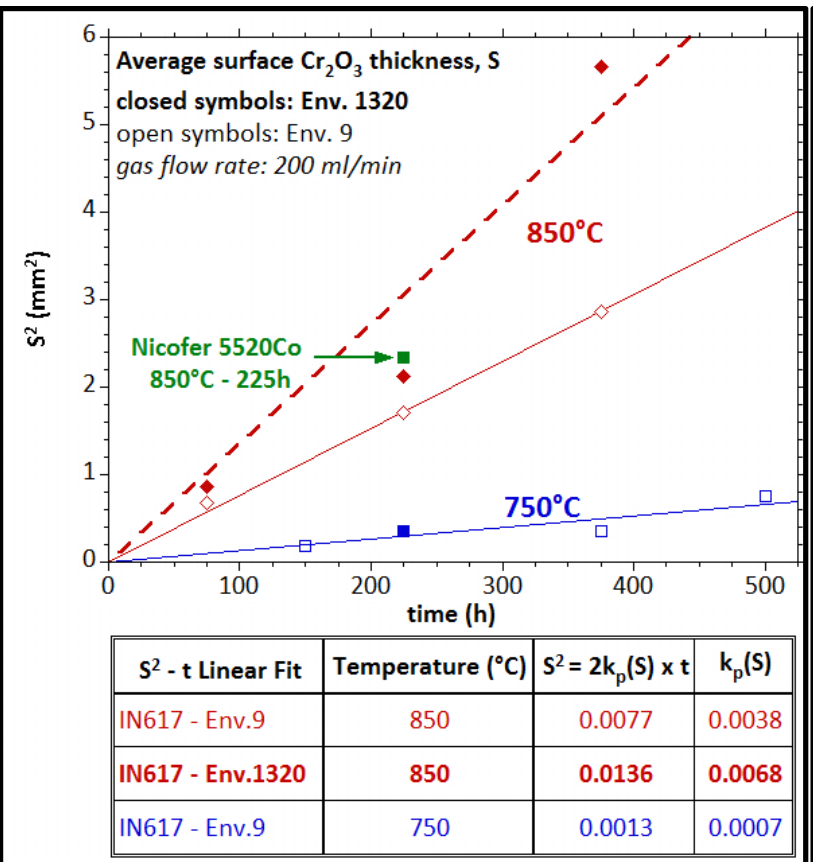

a)

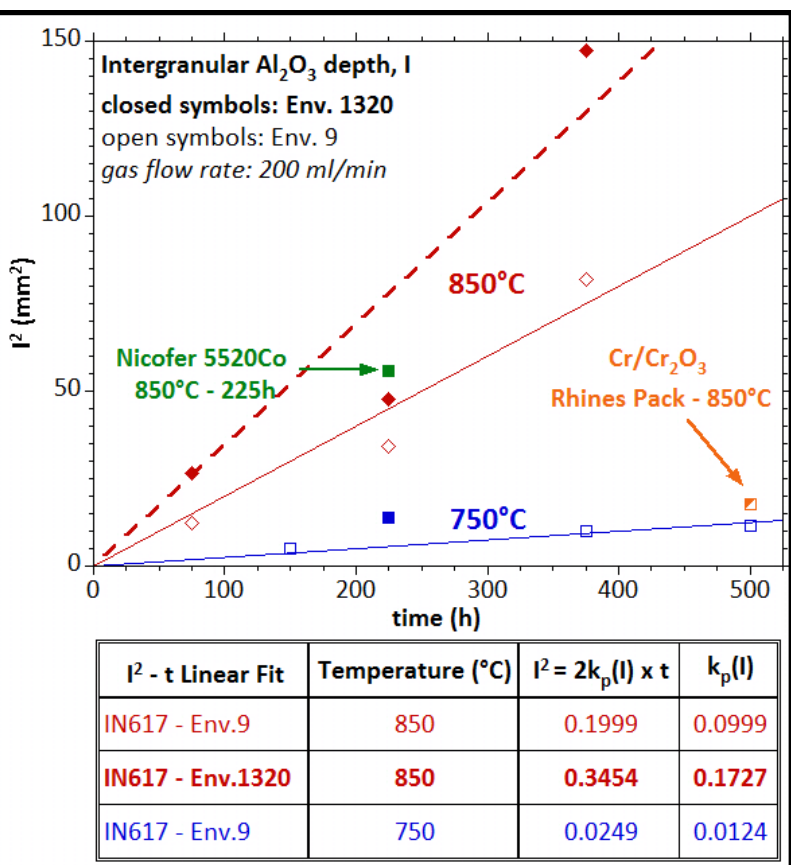

b)

Figure 2. Parabolic surface oxidation (a) and intergranular Al oxidation (b) kinetics of IN617 samples exposed to $\mathrm{He}-\mathrm{CO} / \mathrm{CO}_{2}=9(\mathrm{Pco}=13.5 \mathrm{molppm})$ and $\mathrm{He}-\mathrm{CO} / \mathrm{CO}_{2}=1320(\mathrm{Pco}=1980$ molppm), IN617 Cr- $\mathrm{Cr}_{2} \mathrm{O}_{3}$ Rhines Pack samples tested at $850^{\circ} \mathrm{C}$ for $500 \mathrm{~h}$, and Nicrofer $5520 \mathrm{Co}$ sample exposed to $\mathrm{He}-\mathrm{CO} / \mathrm{CO}_{2}=1320(\mathrm{Pco}=1980 \mathrm{molppm})$ at $850^{\circ} \mathrm{C}$ for $225 \mathrm{~h} . k_{P}(S)$ and $k_{P}(I)$ denote the surface and intergranular oxidation rate constants in units $\mu \mathrm{m}^{2} / \mathrm{h}$, respectively. 


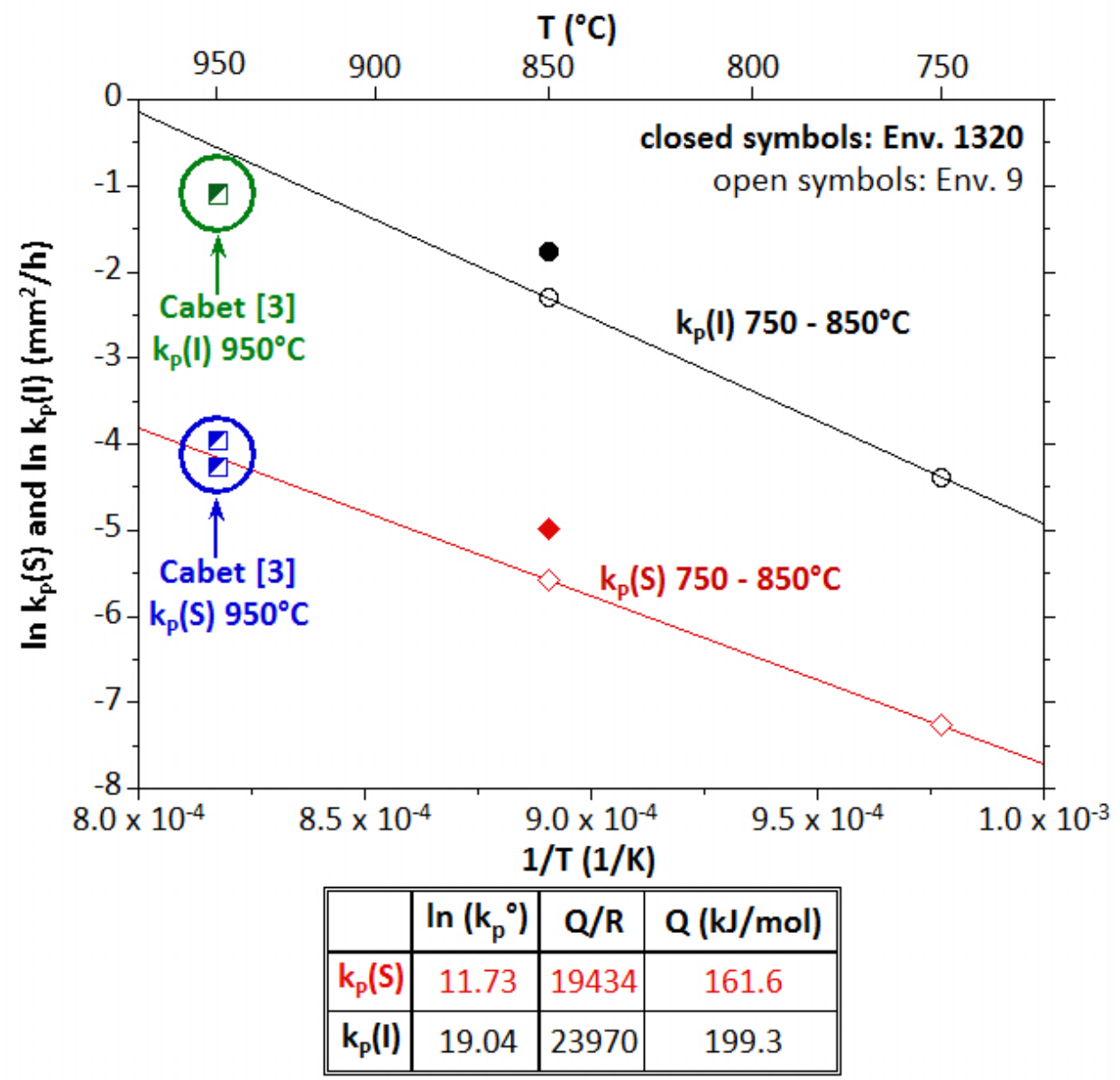

Figure 3. Comparison of the measured parabolic rate constants for IN617 surface and intergranular $\mathrm{Al}$ oxidation upon exposure to $\mathrm{He}-\mathrm{CO} / \mathrm{CO}_{2}=9(\mathrm{Pco}=13.5 \mathrm{molppm})$ and $\mathrm{He}$ $\mathrm{CO} / \mathrm{CO}_{2}=1320(\mathrm{Pco}=1980 \mathrm{molppm})$ at 750 and $850^{\circ} \mathrm{C}$ with the data reported by Cabet and Duprey at $950^{\circ} \mathrm{C}[3]$. Q values denote the activation energy for surface and intergranular $\mathrm{Al}$ oxidation. 


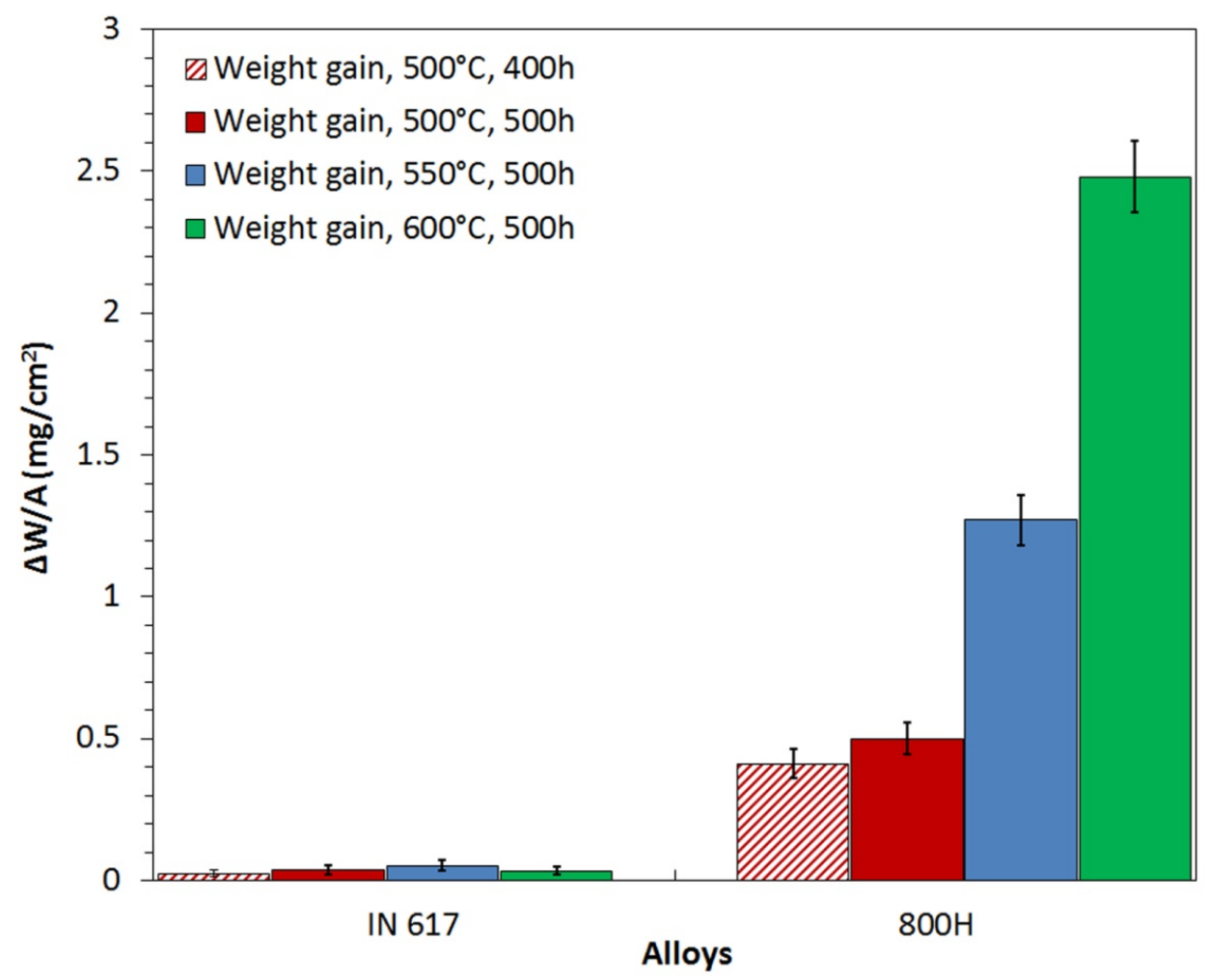

Figure 4. Weight gains measured for IN617 and 800H samples exposed to deaerated SCW at 500 $-600^{\circ} \mathrm{C}$ for up to $500 \mathrm{~h}$. 


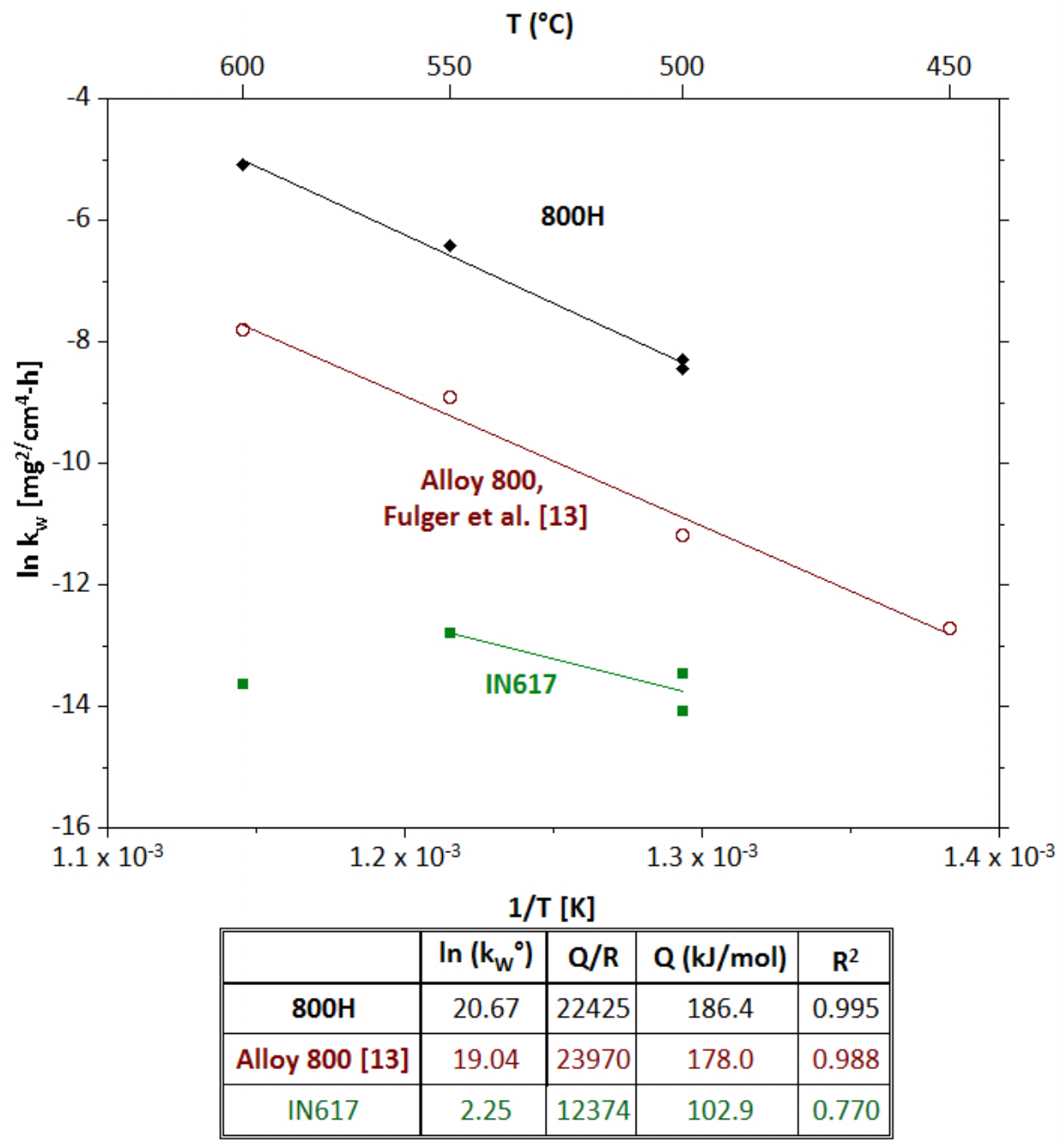

Figure 5. Comparison of the measured parabolic rate constants for oxidation of IN617 and $800 \mathrm{H}$ in deaerated SCW at $500-600^{\circ} \mathrm{C}$ with the data reported by Fulger et al. for the oxidation of Alloy800 in deaerated SCW at $450-600^{\circ} \mathrm{C}$ [13]. Q values denote the activation energy for oxidation. 


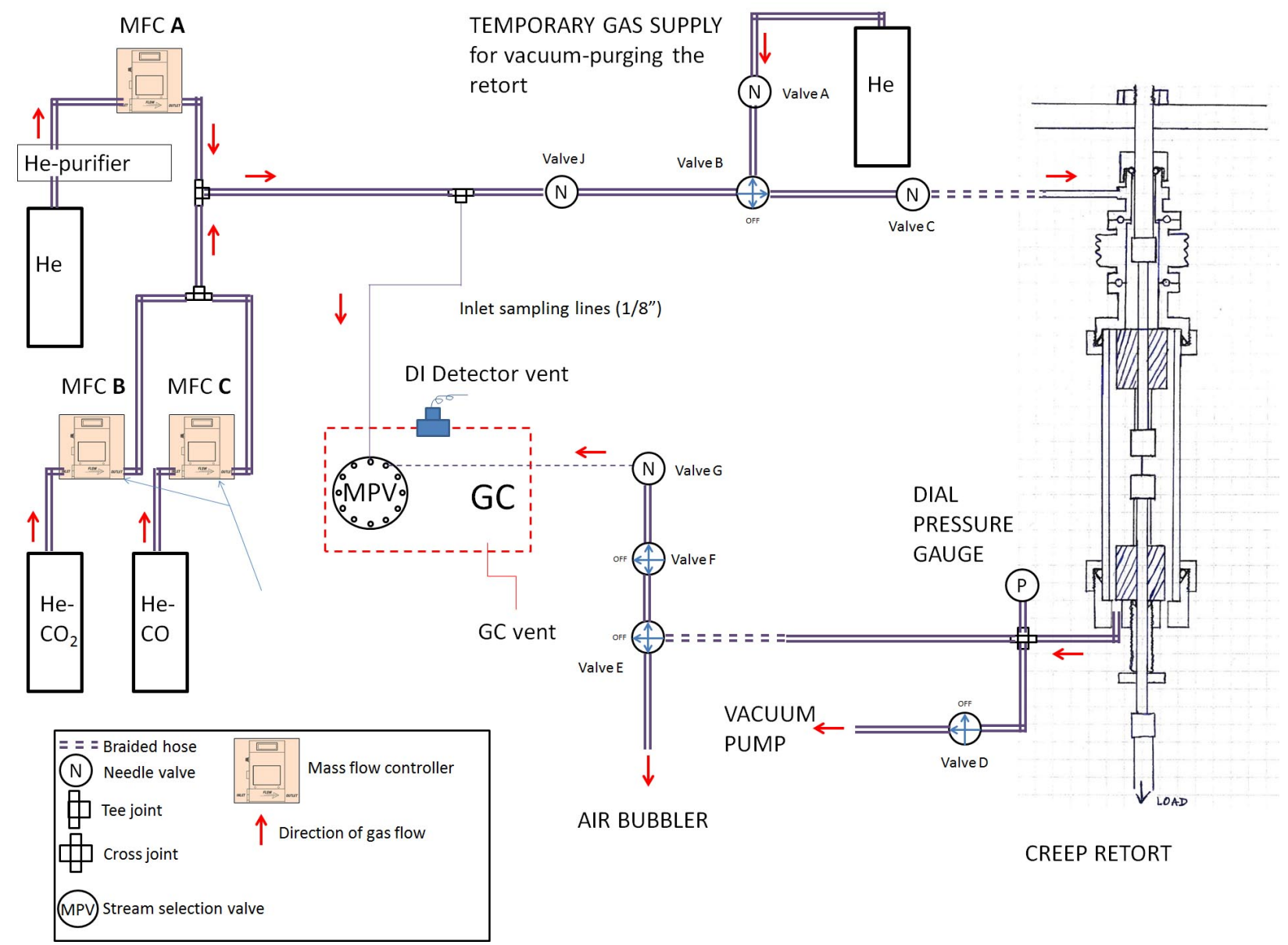

Figure 6. Schematic of the Controlled-Impurity-Flow Creep system. The three major sections: gas mixing section (MFCs), exposure-mechanical testing section (creep retort), and the gas analysis section (GC). 


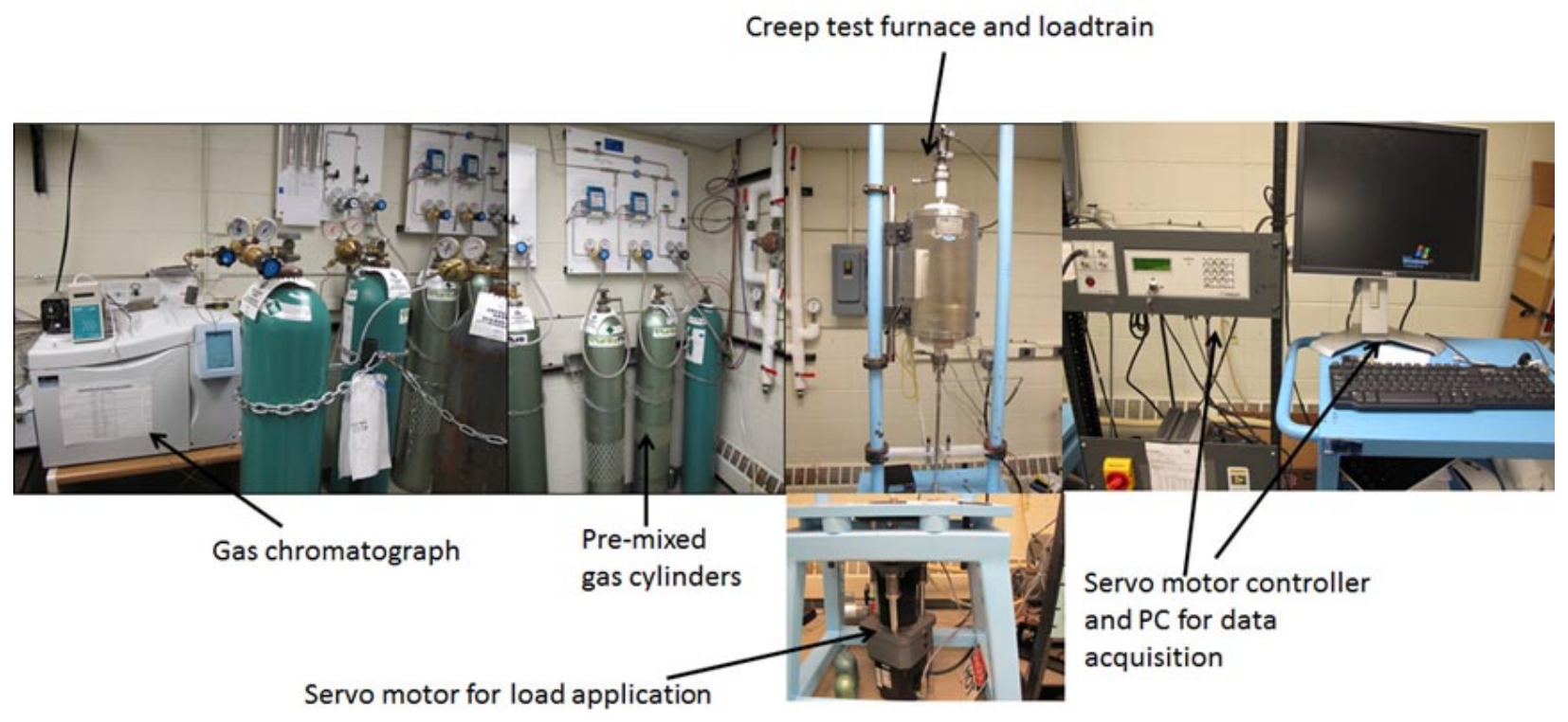

Figure 7. Photograph of the assembled Controlled-Impurity-Flow Creep system.

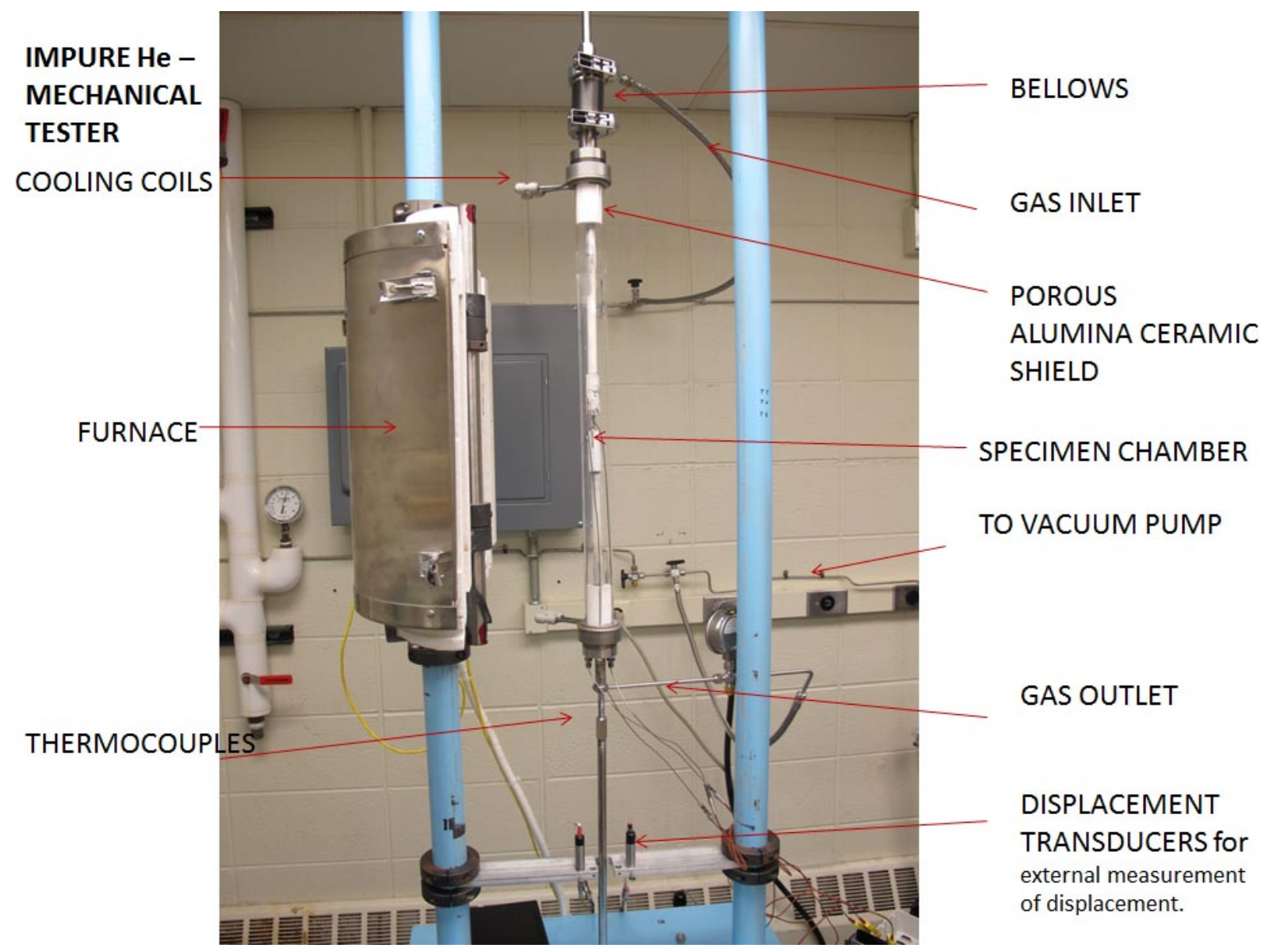

Figure 8 . The custom built creep frame for exposure-mechanical tests in impure helium environments. 


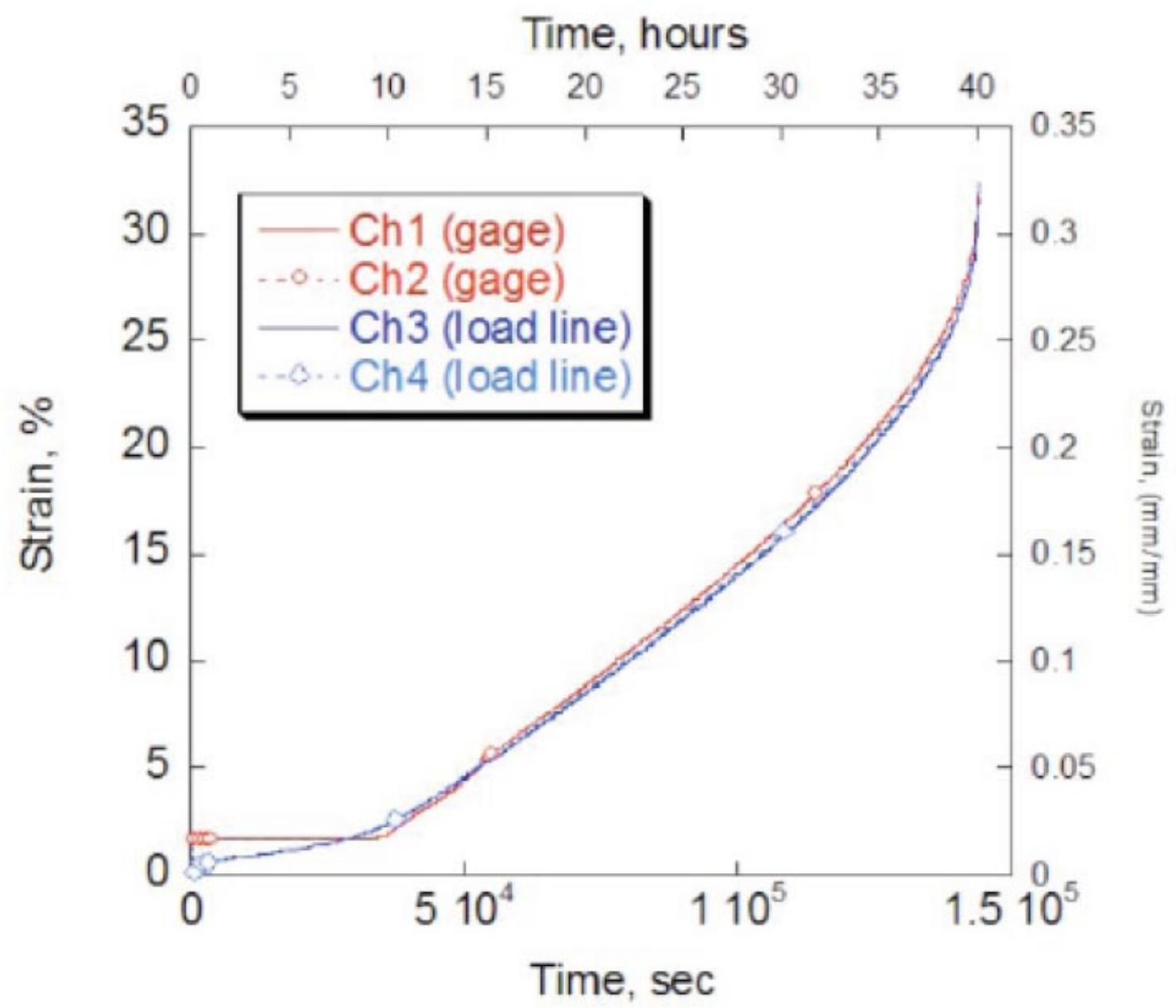

Figure 9. Strain versus time data for Alloy 617. Ch1 and Ch2: gauge displacement; Ch3 and Ch4: load line displacement. 

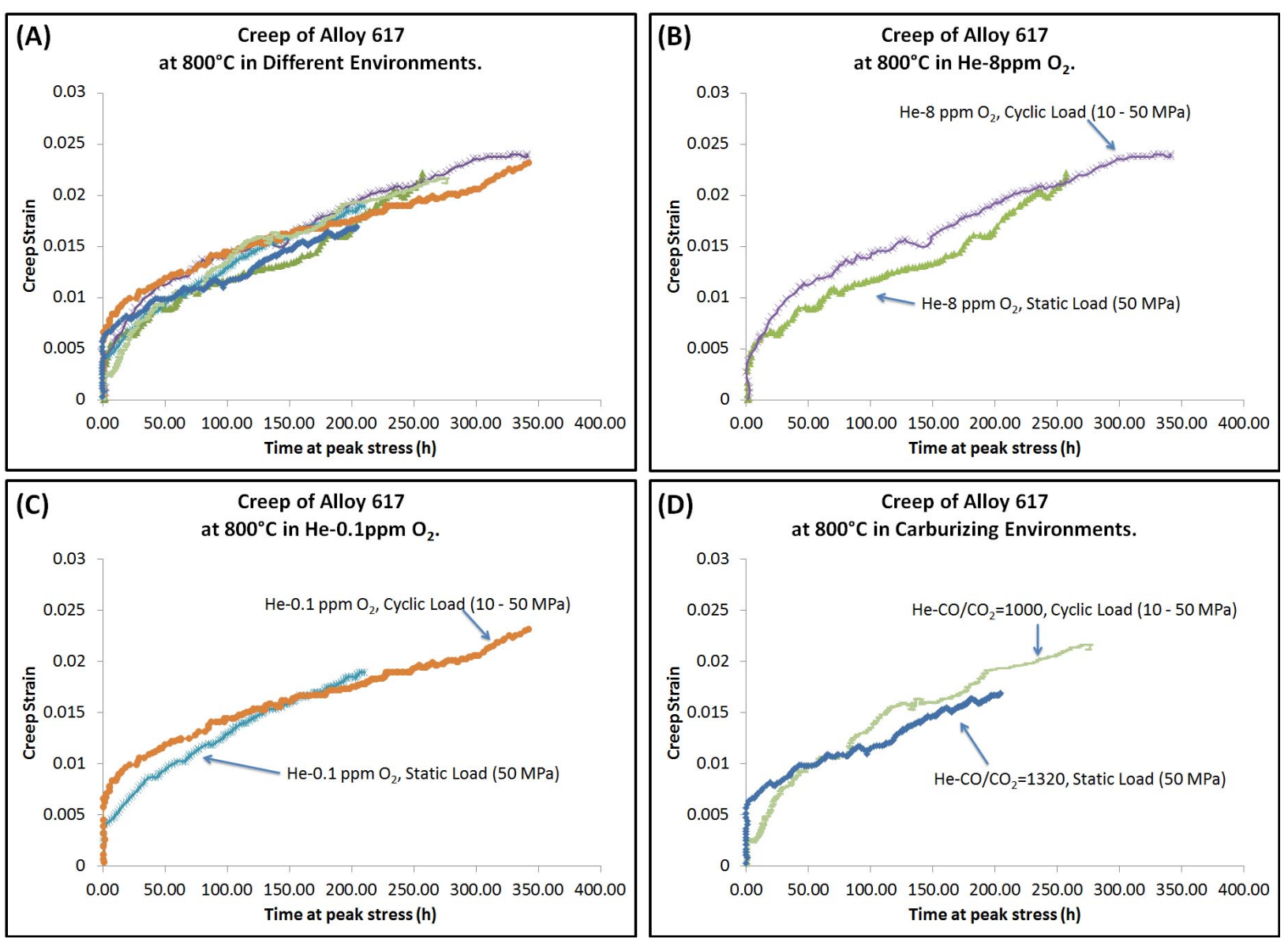

Figure 10. Creep curves of Alloy 617 at $800^{\circ} \mathrm{C}$ in different environments. Six creep curves in three different environments are plotted in $\mathrm{A}$, and the curves for each environment and load are shown in B, C and D keeping the same color coding. Two tests (static and cyclic load) were conducted for each of the He-8ppm $\mathrm{O}_{2}, \mathrm{He}-0.1 \mathrm{ppm} \mathrm{O}_{2}$, and $\mathrm{He}-\mathrm{CO} / \mathrm{CO}_{2}=1320$ environments. 

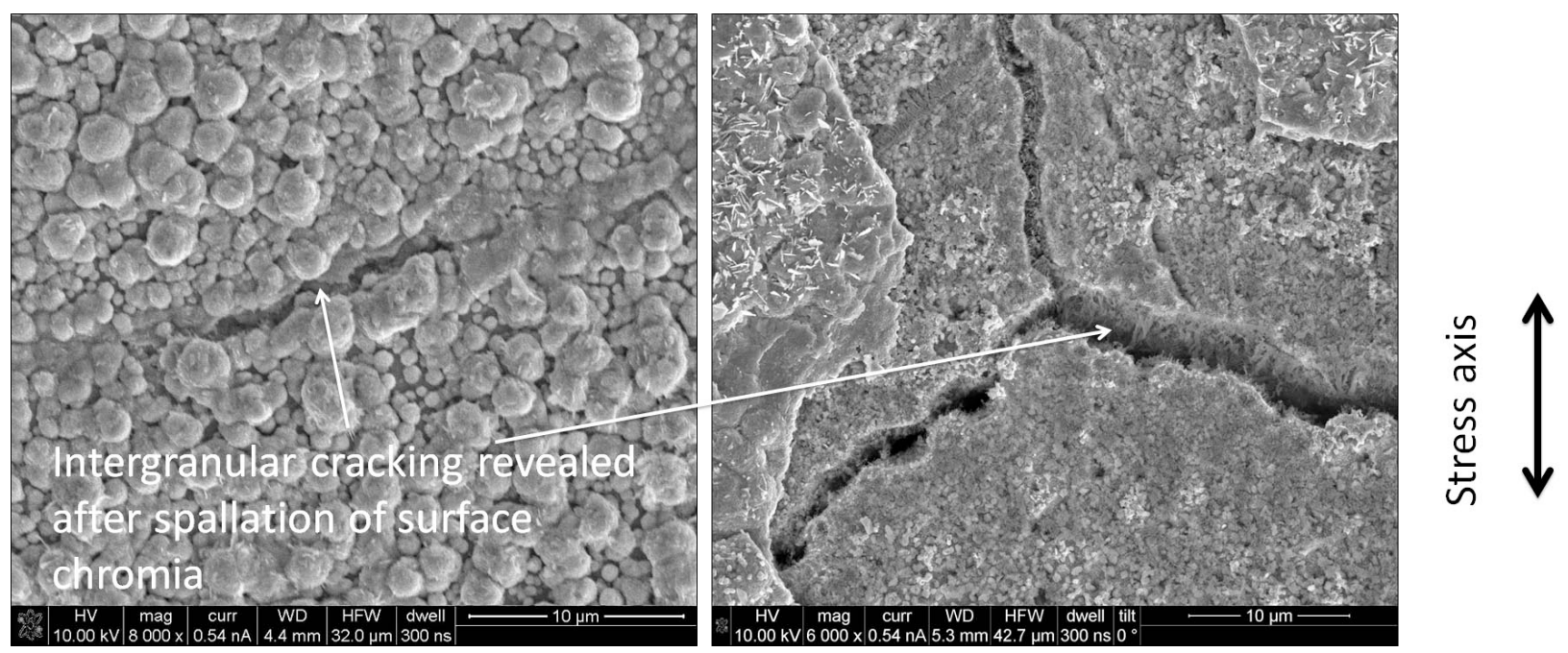

Figure 11. SEM images showing surface damage of Alloy 617 crept at $800^{\circ} \mathrm{C}$ in $\mathrm{He}-8 \mathrm{ppm} \mathrm{O}_{2}$.
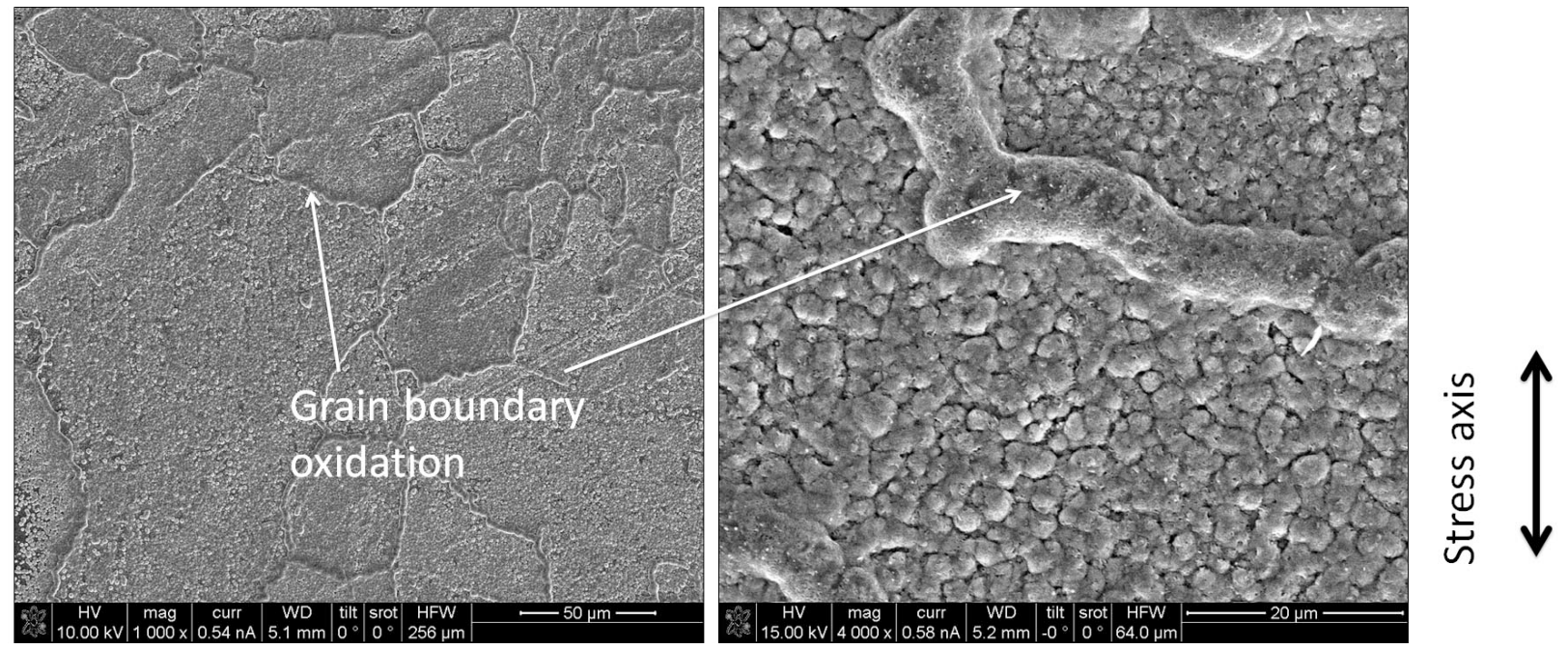

Figure 12. SEM images showing surface damage of Alloy 617 crept at $800^{\circ} \mathrm{C}$ in $\mathrm{He}-<0.1 \mathrm{ppm} \mathrm{O}_{2}$. 

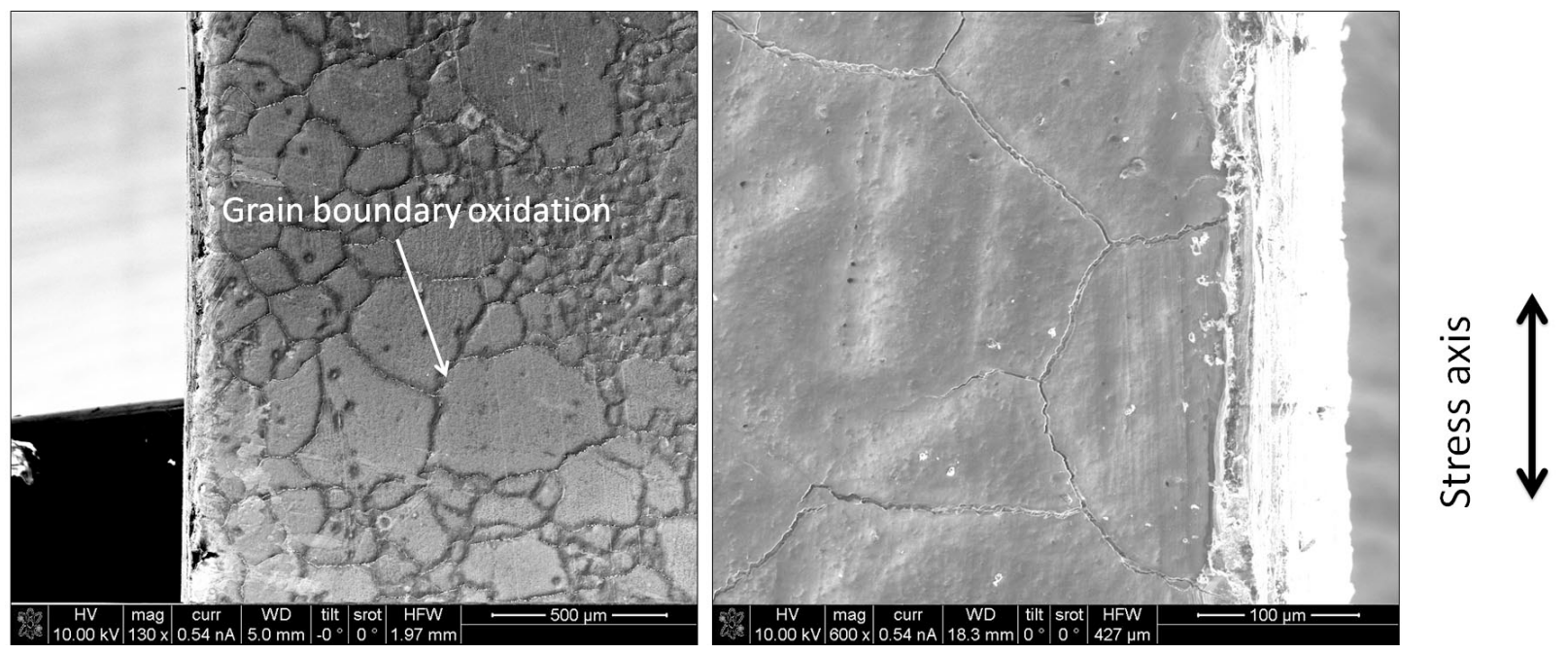

Figure 13. SEM images showing surface damage of Alloy 617 crept at $800^{\circ} \mathrm{C}$ in $\mathrm{He}$ $\mathrm{CO} / \mathrm{CO}_{2}=1320$.

$\mathrm{He}-8 \mathrm{ppm} \mathrm{O}_{2}$ Static Creep (50 MPa)

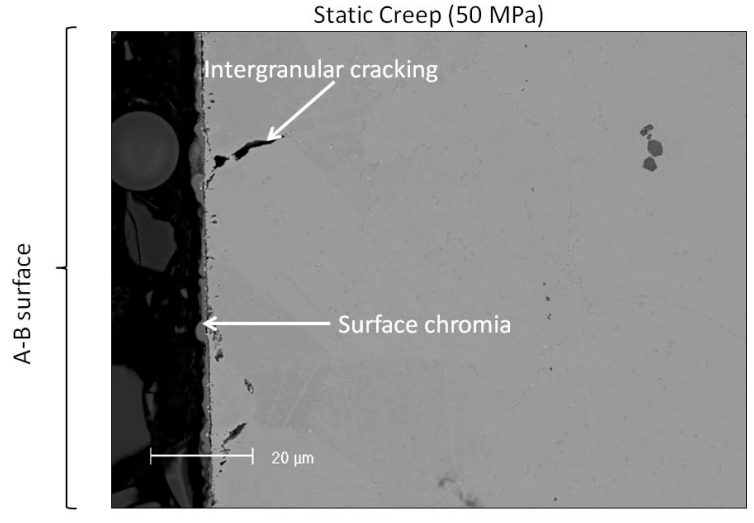

He-8ppm $\mathrm{O}_{2}$ Cyclic Creep (10-50 MPa)

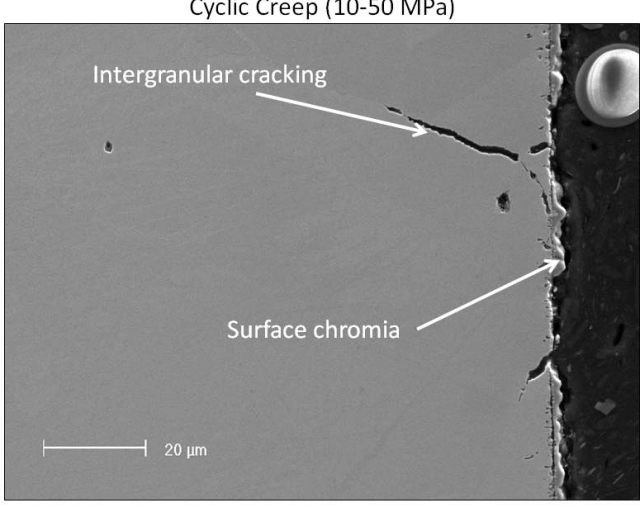

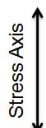
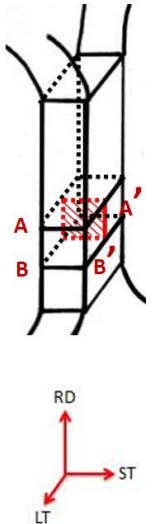

Figure 14. SEM images showing characterization of internal damage of Alloy 617 crept at $800^{\circ} \mathrm{C}$ in $\mathrm{He}-8 \mathrm{ppm} \mathrm{O}_{2}$. 

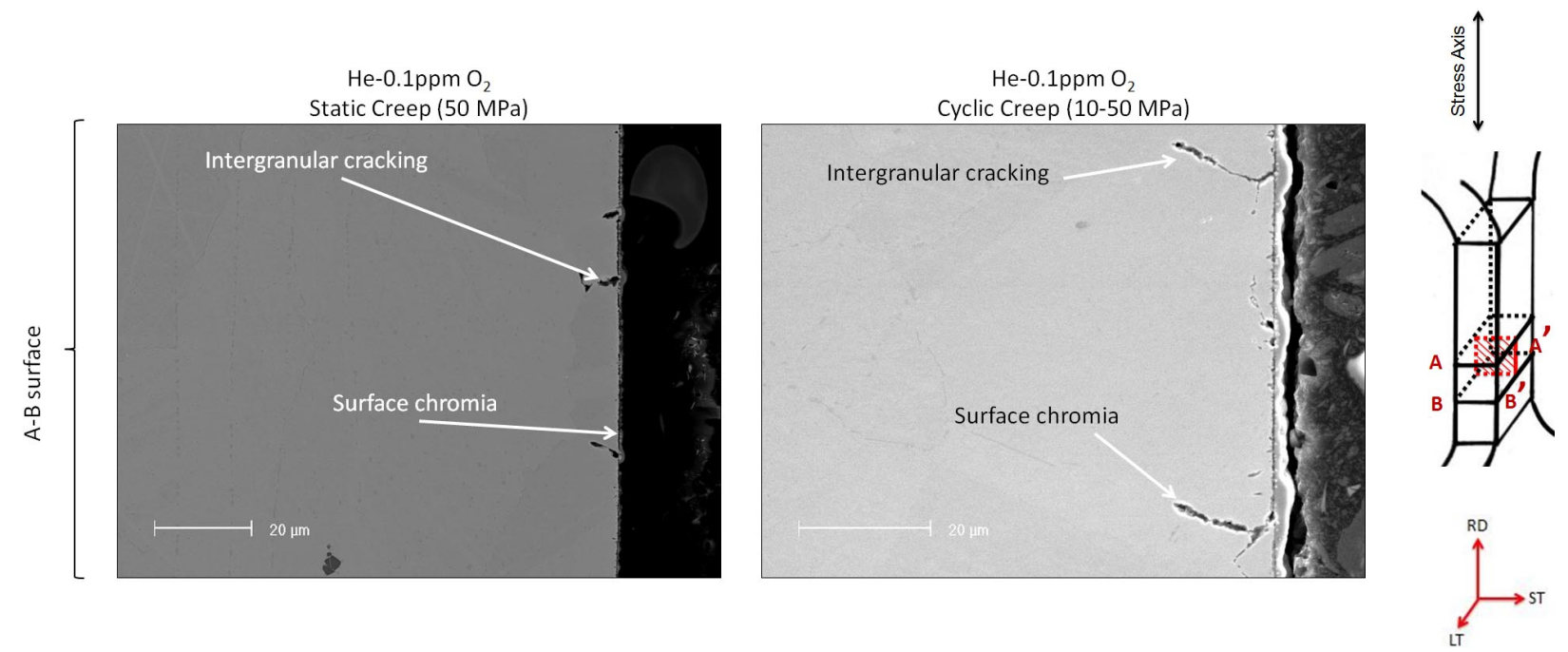

Figure 15. SEM images showing characterization of internal damage of Alloy $617 \mathrm{crept}$ at $800^{\circ} \mathrm{C}$ in $\mathrm{He}-<0.1 \mathrm{ppm} \mathrm{O}_{2}$.
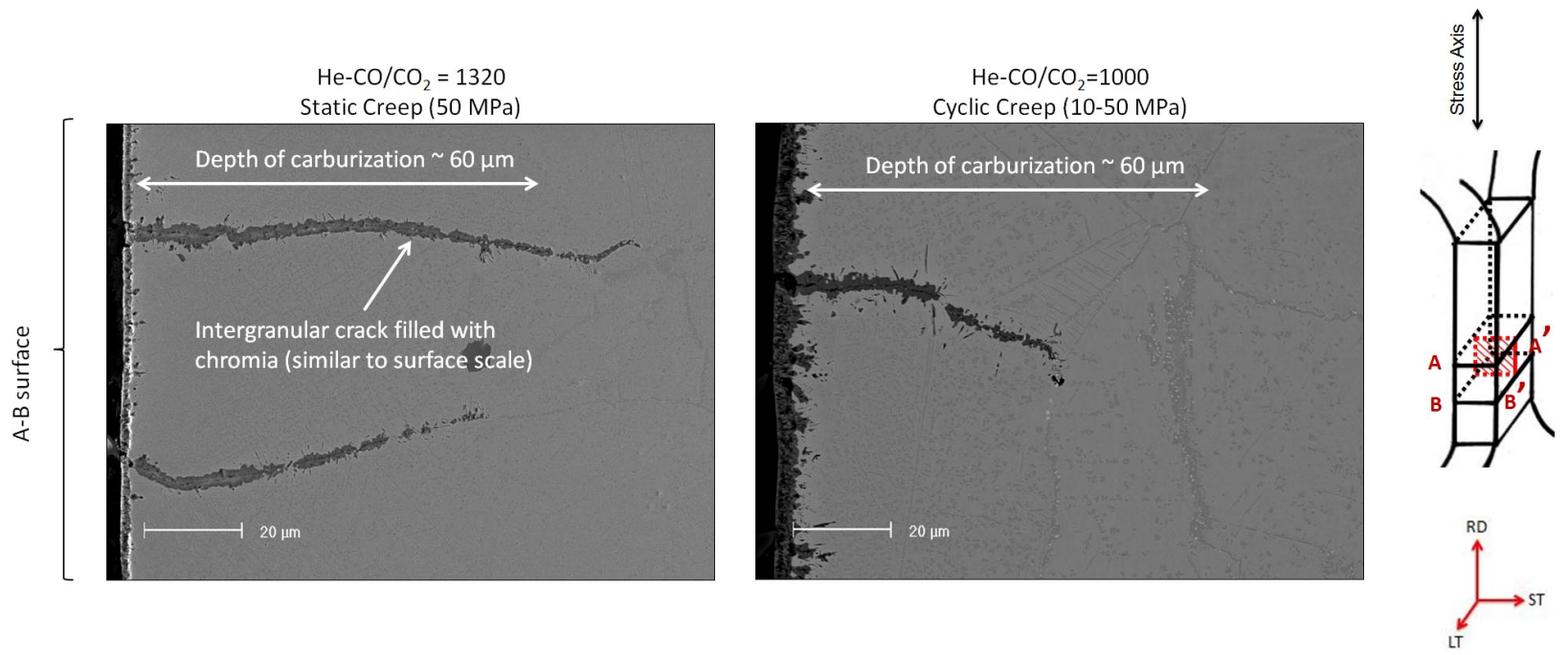

Figure 16. SEM images showing characterization of internal damage of Alloy $617 \mathrm{crept}$ at $800^{\circ} \mathrm{C}$ in $\mathrm{He}-\mathrm{CO} / \mathrm{CO}_{2}=1320$. 


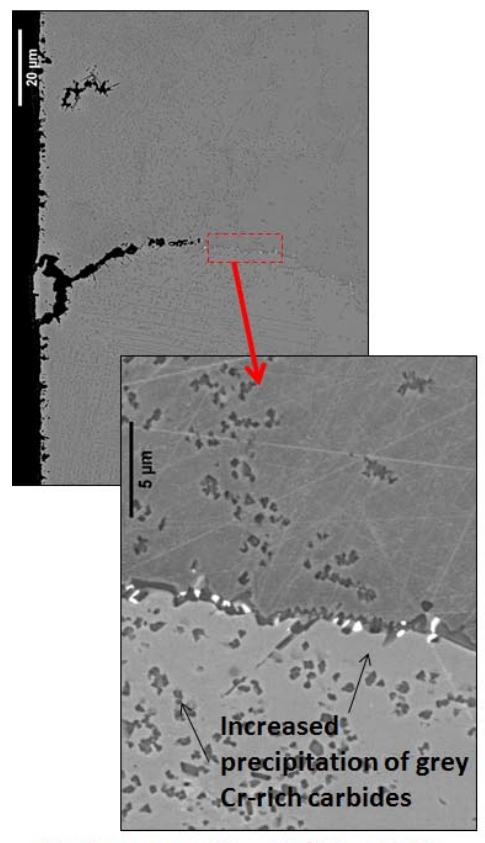

Environment: $\mathrm{He}-\mathrm{CO} / \mathrm{CO}_{2}=1320$

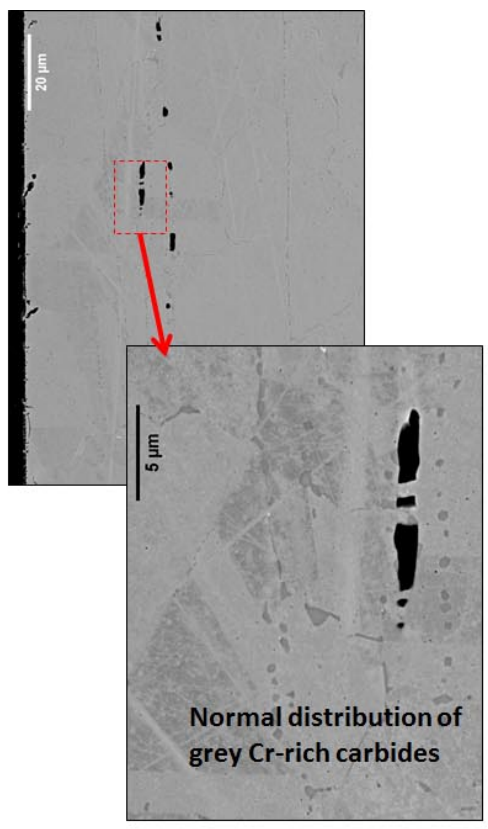

Environment: $\mathrm{He}-0.1 \mathrm{ppmO}_{2}$
Environment: $\mathrm{He}-8 \mathrm{ppmO}_{2}$

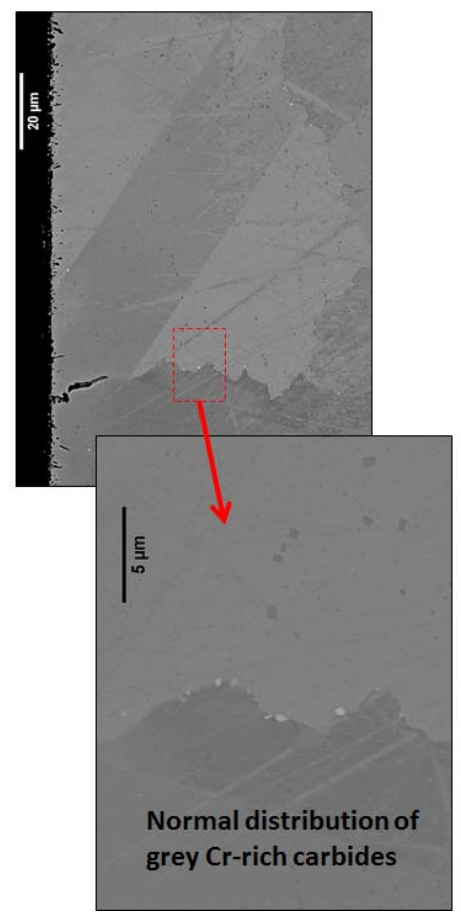

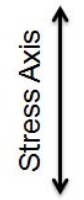
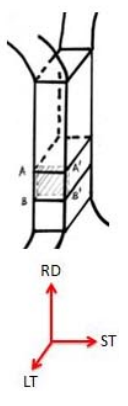

Figure 17. High magnification of SEM images of Alloy 617 statically crept at $50 \mathrm{MPa}$ and $800^{\circ} \mathrm{C}$ in three different environments. Note the precipitation of internal carbides in $\mathrm{He}-\mathrm{CO} / \mathrm{CO}_{2}=1320$ environment. 


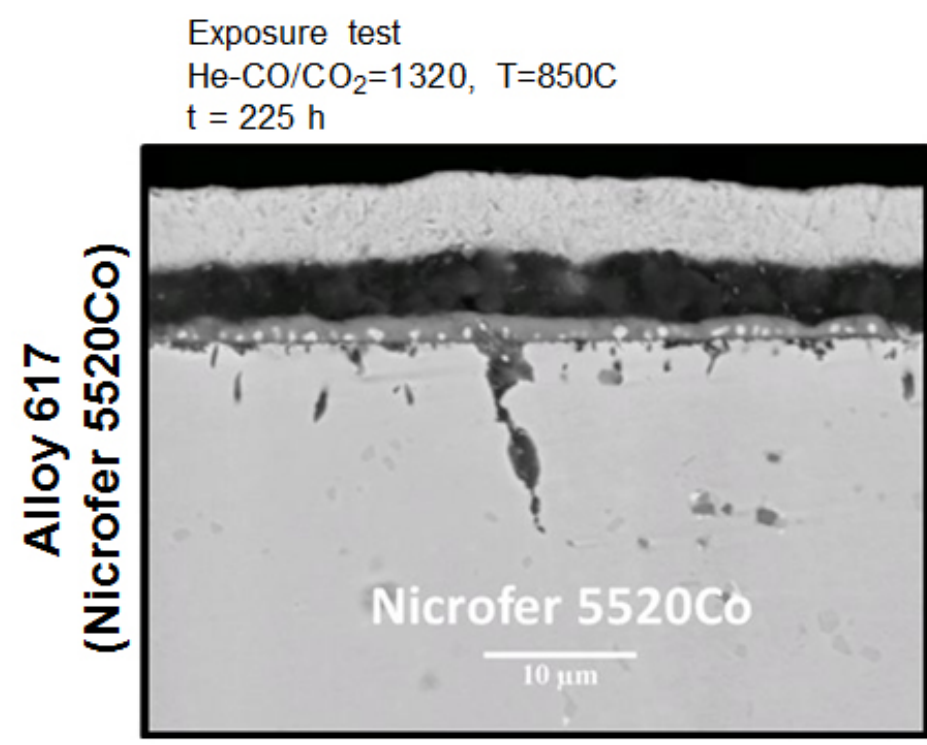

Static Creep (50 MPa)

A $\mathrm{He}-\mathrm{CO} / \mathrm{CO}_{2}=1320, \mathrm{~T}=800 \mathrm{C}, \quad \mathrm{A}^{\prime}$ $\varepsilon=1.7 \%, t=206 h$

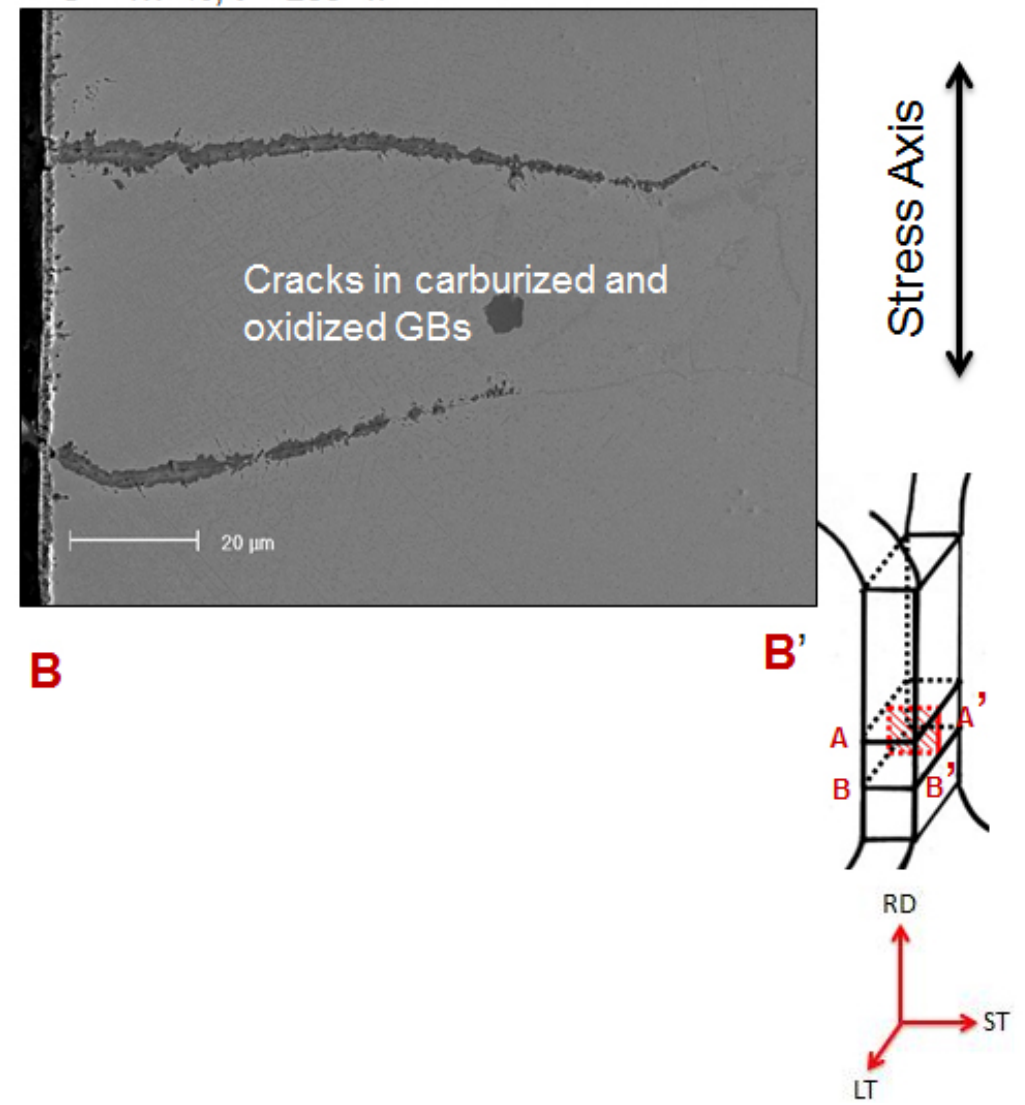

Figure 18. Effect of stress/strain during exposure of Alloy 617 only exposed (top) and both crept and exposed to $\mathrm{He}-\mathrm{CO} / \mathrm{CO}_{2}=1320$. 